\title{
Pricing Rule in a Clock Auction
}

\author{
Peter Cramton, Pacharasut Sujarittanonta \\ Department of Economics, University of Maryland, College Park, Maryland 20742 \\ \{pcramton@gmail.com, sujarittanonta@econ.umd.edu\}
}

\begin{abstract}
$\mathrm{W}$ e analyze a discrete clock auction with lowest-accepted-bid (LAB) pricing and provisional winners, as adopted by India for its $3 \mathrm{G}$ spectrum auction. In a perfect Bayesian equilibrium, the provisional winner shades her bid, whereas provisional losers do not. Such differential shading leads to inefficiency. An auction with highest-rejected-bid (HRB) pricing and exit bids is strategically simple, has no bid shading, and is fully efficient. In addition, it has higher revenues than the LAB auction, assuming profit-maximizing bidders. The bid shading in the LAB auction exposes a bidder to the possibility of losing the auction at a price below the bidder's value. Thus, a fear of losing at profitable prices may cause bidders in the LAB auction to bid more aggressively than predicted, assuming profit-maximizing bidders. We extend the model by adding an anticipated loser's regret to the payoff function. Revenue from the LAB auction yields higher expected revenue than the HRB auction when bidders' fear of losing at profitable prices is sufficiently strong. This would provide one explanation why India, with an expressed objective of revenue maximization, adopted the LAB auction for its upcoming $3 \mathrm{G}$ spectrum auction, rather than the seemingly superior HRB auction.
\end{abstract}

Key words: auctions; clock auctions; spectrum auctions; behavioral economics; market design

History: Received on April 16, 2009. Accepted by L. Robin Keller and guest editors Robert F. Bordley and

Elena Katok on September 21, 2009, after 1 revision. Published online in Articles in Advance November 6, 2009.

\section{Introduction}

In 2008, the government of India announced that radio spectrum for $3 \mathrm{G}$ mobile services would be auctioned in 2009. The $2.1 \mathrm{GHz}$ spectrum is to be sold as paired spectrum $(2 \times 5 \mathrm{MHz}$ blocks $)$ in each of 22 regions covering India. There are one to four lots available in each region, and each bidder can obtain at most one lot per region. The government's stated objective for the auction emphasizes revenue maximization rather than efficiency. In December 2008, the government announced the chosen auction design: a discrete clock auction with lowest-accepted-bid (LAB) pricing and provisional winners (Ministry of Communications and Information Technology 2008). Here we examine the equilibrium properties of such an auction in a simplified setting. As a comparison, we analyze a discrete clock auction with highestrejected-bid (HRB) pricing and exit bids. This format is often used in high-stakes auctions in practice (Ausubel and Cramton 2004).

Interestingly, with profit-maximizing bidders, we find the HRB auction dominates the LAB auction in both efficiency and revenues. The HRB with exit bids is fully efficient, because it is a dominant strategy to bid up to one's valuation. In contrast, LAB with provisional winners has differential shading, because a provisional winner shades her bid, whereas a provisional loser does not. This differential shading creates an inefficiency and reduces revenues. Given this strong theoretical result, it may seem odd that India chose the LAB format.

One potential explanation comes from behavioral economics. If bidders anticipate the regret of losing at a profitable price, they may be reluctant to shade bids as a provisional winner. This fear of losing has been shown to explain overbidding in first-price, sealedbid auctions (Engelbrecht-Wiggans 1989; Filiz-Ozbay and Ozbay 2007; Engelbrecht-Wiggans and Katok $2007,2008)$. Risk aversion is an alternative explanation for overbidding, but has little empirical support (Engelbrecht-Wiggans and Katok 2009). Delgado et al. (2008) provide a neurological foundation that fear of losing, not joy of winning, is the source of overbidding in first-price auctions. Loss aversion with a reference point of winning (Koszegi and Rabin 2006, Lange and Ratan 2010) provides an analogous theory for fear 
of losing. When we extend the standard theory to include a fear of losing, we find that if bidders' fear of losing is sufficiently strong, then the LAB auction revenue dominates the HRB auction. This result provides an explanation for India's selection of a seemingly inferior auction format.

Most theoretical papers on clock auctions assume a continuous clock for convenience. In practice, clock auctions use a discrete price clock, because these auctions typically are conducted on the Internet, and communication is not sufficiently reliable to bind bidders to higher prices with the continuous passage of time. With discrete bid levels, the two predominant pricing rules, lowest accepted bid and highest rejected bid, are distinct, and the auction designer must select a pricing rule as well as other elements of the design. Currently, there is little literature for the auction designer to turn to for help with this issue.

There are a limited number of papers investigating auctions with discrete bid levels. These papers focus on explaining bidding behavior. Chwe (1989) studied the first-price auction with discrete bid levels and showed that the expected revenue is less than its continuous counterpart. Mathews and Sengupta (2008) analyzed a sealed-bid, second-price auction with discrete bids.

More closely related is the work that considers choices of bid levels in ascending auctions. Rothkopf and Harstad (1994) is an important early contribution, determining optimal bid levels that maximize expected revenue in an oral auction. The paper also introduces the trade-off between auction duration and bid increments. David et al. (2007) extend the model of Rothkopf and Harstad and find that decreasing bid increments are optimal. Although the pricing rule in our paper is the same as in Rothkopf and Harstad (1994), the auction formats have important differences, which result in significantly different bidding behavior.

We consider a discrete clock auction with two pricing rules: highest rejected bid and lowest accepted bid. Bidders have independent private values and unit demands. We first analyze bidding behavior in an HRB auction. This is our benchmark for comparing performance with the LAB auction. The HRB auction is a useful benchmark because of its simplicity, its desirable properties (efficiency and truth dominance), and its use in practice. In contrast, the LAB auction forces bidders to engage in difficult trade-offs. We are only able to solve for equilibrium bidding behavior in a simplified setting. Nonetheless, we show that an LAB auction is generally inefficient. Despite this inefficiency, the LAB auction can yield higher revenues if bidders anticipate the regret of losing at profitable prices, and therefore engage in less bid shading than a bidder focused solely on profit maximization.

\section{Discrete Clock Auction with Unit Demand}

There are $K$ identical items for sale to $N$ risk-neutral bidders indexed by $i=1, \ldots, N$, where $N>K$. The seller values the items at zero. Bidder $i$ demands at most one item. Her private valuation for the item is $x_{i}$, which is independently drawn from the distribution $F$ with associated density function $f$ on the interval $[0,1]$. (We use the independent private values model for simplicity. Our main results extend to a model with affiliated values.) Bidder $i$ 's payoff if she wins the item is $x_{i}-m_{i}$, where $m_{i}$ is bidder $i^{\prime} \mathrm{s}$ payment and zero otherwise.

Before the auction starts, the seller announces a vector of bid levels, $\mathbf{P}=\left(P_{0}, P_{1}, \ldots, P_{T-1}\right)$, where $P_{t}$ is the clock price at round $t$ for $t=1,2, \ldots, T-1$, and $T$ is the number of bid levels. The clock price increases every round so that $P_{0}<P_{1}<\cdots<P_{T-1}$. Define the bid increment in round $t$ as $\Delta_{t}=P_{t}-P_{t-1}$ for $t=$ $1,2, \ldots, T-1$. Assume that $P_{0}=0$ and $P_{T-1}=1$. The auction begins in round 1 at a price $P_{1}$. In round $t$, bidder $i$ chooses either to bid at the current clock price, $q_{i t}=1$, or to exit, $q_{i t}=0$. Once a bidder exits, she cannot bid again. Let $Q_{t}=\sum_{i=1}^{N} q_{i t}$ be total demand in round $t$. If there is excess demand, $Q_{t}>K$, the auction proceeds to the next round. The auction ends in the round $t$ such that $Q_{t} \leq K$.

\subsection{Highest Rejected Bid with Exit Bids}

In the HRB format (highest rejected bid with exit bids), if bidder $i$ exits in round $t$, the bidder can submit an exit bid-a price between $P_{t-1}$ and $P_{t}$ at which she wants to exit. In round $t$ such that $Q_{t}=K$, the items are awarded to the $K$ active bidders and the final price is the highest exit bid among the inactive bidders. If $Q_{t}<K$, the items are awarded to the $Q_{t}$ active bidders and to those bidders who submitted 
the $\left(K-Q_{t}\right)$-highest exit bids. The final price is the $\left(K-Q_{t}+1\right)$-highest exit bid.

Proposition 1. In the HRB auction, truthful bidding (bidding up to one's valuation) is a weakly dominant strategy. Therefore, the HRB auction yields an efficient allocation. Each of the (K)-highest valuation bidders wins and pays the $(K+1)$-highest valuation.

This result follows immediately from the unit demand setting and the ability to submit exit bids at actual valuations. Unit demand guarantees that each winner pays the Vickrey price, thereby inducing truthful bidding. Because all bidders bid truthfully, the items are awarded to the bidders who value them the most.

\subsection{Lowest Accepted Bid with Provisional Winners}

In the LAB format (lowest accepted bid with provisional winners), if there is excess demand in any round, the seller randomly selects $K$ provisional winners for the next round from active bidders and ranks them from $K$ to one (highest rank is given priority). Other remaining active bidders are designated as provisional losers (a rank of 0 ) for the next round. Each bidder is automatically assigned a rank in round 1 .

The auction ends if there is no excess demand. The items are awarded to the active bidders and the remaining items are awarded to the inactive provisional winner in the current round with the highest rank, and so on until all items are sold. Because bidders are not allowed to submit exit bids, the final price and bids are restricted to clock prices. The final price is uniform and determined by the $(K)$-highest winner's bid. If $Q_{t}=K$, the final price is $P_{t}$, and if $Q_{t}<K$, the final price is $P_{t-1}$. Notice that the ranking is relevant in determining the allocation only when $Q_{t}<K$, because then there is excess supply at the final price $P_{t-1}$. Let $\boldsymbol{\theta} \equiv\{0,1, \ldots, K\}$ be the set of all possible ranks and $\boldsymbol{\Theta}_{t} \equiv\left\{\mathbf{X}_{t} \mid \mathbf{X}_{t} \in \boldsymbol{\theta}^{t}\right\}$ be the set of all possible bidder's ranking histories up from round 1 to round $t$. Let $R_{i t} \in \boldsymbol{\theta}$ denote bidder $i$ 's rank in round $t$ and $\mathbf{H}_{i t} \equiv\left(R_{i 1}, R_{i 2}, \ldots, R_{i t}\right) \in \Theta_{t}$ be a vector of bidder $i$ 's ranking history from round 1 to round $t$. Bidder $i$ 's ranking history $\mathbf{H}_{i t}$ is known only to the bidder $i$.

One important difference between the LAB auction described here and an ascending bid auction with the
Table 1 LAB Auction with Three Bidders and Two Items in Round $t$

\begin{tabular}{|c|c|c|c|c|}
\hline Case & $\begin{array}{l}\text { Bidder } 1 \\
\left(R_{1 t}=0\right)\end{array}$ & $\begin{array}{c}\text { Bidder } 2 \\
\left(R_{2 t}=1\right)\end{array}$ & $\begin{array}{l}\text { Bidder } 3 \\
\left(R_{3 t}=2\right)\end{array}$ & Outcome \\
\hline 1 & Bid & Bid & Bid & $\begin{array}{l}\text { Proceed to round } t+1 \text {, and } \\
\text { provisional winners are } \\
\text { reselected }\end{array}$ \\
\hline 2 & Bid & Bid & Exit & $\begin{array}{l}\text { Bidders } 1 \text { and } 2 \text { win, and the } \\
\text { final price is } P_{t}\end{array}$ \\
\hline 3 & Bid & Exit & Bid & $\begin{array}{l}\text { Bidders } 1 \text { and } 3 \text { win, and the } \\
\text { final price is } P_{t}\end{array}$ \\
\hline 4 & Exit & Bid & Bid & $\begin{array}{l}\text { Bidders } 2 \text { and } 3 \text { win, and the } \\
\text { final price is } P_{t}\end{array}$ \\
\hline 5 & Bid & Exit & Exit & $\begin{array}{l}\text { Bidders } 1 \text { and } 3 \text { win, and the } \\
\text { final price is } P_{t-1}\end{array}$ \\
\hline 6 & Exit & Bid & Exit & $\begin{array}{l}\text { Bidders } 2 \text { and } 3 \text { win, and the } \\
\text { final price is } P_{t-1}\end{array}$ \\
\hline 7 & Exit & Exit & Bid & $\begin{array}{l}\text { Bidders } 2 \text { and } 3 \text { win, and the } \\
\text { final price is } P_{t-1}\end{array}$ \\
\hline 8 & Exit & Exit & Exit & $\begin{array}{l}\text { Bidders } 2 \text { and } 3 \text { win, and the } \\
\text { final price is } P_{t-1}\end{array}$ \\
\hline
\end{tabular}

same pricing rule is that in the LAB auction, a provisional winner must keep topping her own bid to be eligible to bid in subsequent rounds. In contrast, in an ascending bid auction with $\mathrm{LAB}$, being a provisional winner is counted as being active. Therefore, a provisional winner does not need to bid to be eligible to bid in the subsequent rounds.

To better illustrate the LAB pricing rule with ranking, consider an auction with three bidders and two items for sale. Suppose all bidders bid in round $t-1$, and bidders 2 and 3 are selected as provisional winners with ranks of 1 and 2, respectively, whereas bidder 1 is a provisional loser. In round $t$, eight possible combinations of bids and corresponding allocations and final prices are shown in Table 1. If all bidders bid (Case 1), the auction proceeds to round $t+1$ with a price of $P_{t+1}$, and all bidders are assigned new ranks. Regardless of ranking, if there are exactly two active bidders (Cases 2-4), they win the items at the current clock price $P_{t}$. If there is only one active bidder, which creates an excess supply at the current clock price $P_{t}$ (Cases 5-7), the item is awarded to the active bidder and an inactive provisional winner with highest rank at the previous clock price $P_{t-1}$. Finally, if there is no active bidder (Case 8), bidders 2 and 3 who hold the highest ranks win at the previous clock price $P_{t-1}$.

Lemma 1 . For $K \geq 1$, in any round $t>s+1$ with any ranking history $\mathbf{H}_{i t} \in \Theta_{t}$, bidder $i$ with valuation $x_{i}<P_{s+1}$ exits. 
This lemma simply states that a bidder with a valuation less than $P_{s+1}$ never bids at a price $P_{s+2}$ or above. In some situations, a bidder may take a risk by bidding in round $s+1$ at a price $P_{s+1}$, which is higher than her valuation, in the hope that there will be excess supply and she will consequently win the item at the previous clock price $P_{s}$. When she finds out that the auction actually continues to round $s+2$, it is a dominant strategy to exit immediately regardless of her ranking because the lowest possible final price is $P_{s+1}$, which is still higher than her valuation.

Lemma 2. For $K \geq 1$, in round $t=1,2, \ldots, T-1$ with any ranking history $\mathbf{H}_{i t} \in \Theta_{t}$, a provisional loser with valuation $x_{i}$ bids if $x_{i} \geq P_{t}$. For $K>1$, in round $t=$ $1,2, \ldots, T-1$ with some ranking history $\mathbf{H}_{i t} \in \Theta_{t}$, a provisional loser with valuation $x_{i}<P_{t}$ bids in round $t$ if $x_{i}$ is sufficiently close to $P_{t}$.

For a provisional loser, exiting yields a payoff of zero, whereas bidding yields a positive expected payoff as long as her valuation is above the current clock price. Thus, a provisional loser never exits if her valuation exceeds the current clock price. For some ranking history, a provisional loser may bid at a price level above her valuation because there is a positive probability that less than $K-1$ bids are submitted, and that by bidding she can win the item at the previous clock price, which is below her valuation. However, such a strategy entails a risk of winning the item at a price higher than her valuation. Because a provisional loser's valuation is closer to $P_{t}$, the negative payoff she may receive if the auction continues is smaller, whereas the positive payoff in case that she wins is larger. Therefore, a provisional loser who has a valuation closer to $P_{t}$ may find that bidding is more attractive. If she does not win, she will exit in round $t+1$, according to Lemma 1.

Consider the example in Table 1. Suppose bidder 1 has a valuation between $P_{t-1}$ and $P_{t}$. If she bids and bidders 2 and 3 exit, as in Case 5, which has a positive probability of occurring, bidder 1 wins the item at $P_{t-1}$, gaining a positive payoff. If bidder 1 bids and either bidder 2 or bidder 3 bid, as in Cases 2 or 3, bidder 1 wins the item at $P_{t}$, receiving a negative payoff. If all bidders bid, bidder 1 will exit according to Lemma 1.

LeMmA 3. For $K \geq 1$, there exists a round $t \leq s$ with some ranking history $\mathbf{H}_{i t} \in \Theta_{t}$ such that a provisional winner with a valuation $x_{i} \geq P_{s}$ exits if $x_{i}$ is sufficiently close to $P_{s}$.

Intuitively, a provisional winner faces the first-price incentive - an incentive to keep the price low-which results in exiting before her valuation is reached. A provisional winner can win the item at a lower price if she exits, but she risks losing at a profitable price because exiting is irrevocable. In contrast, if she stays in the auction, her probability of winning the item increases and so does the expected final price she pays. Hence, a provisional winner may find that exiting yields higher expected payoff than bidding.

In addition, a provisional winner with higher rank faces less risk of losing when exiting because a greater number of new bids are required to displace her provisional winning bid. Consequently, there is some ranking history such that a provisional winner with a particular valuation bids if her rank is less than $r$, but one with the same valuation exits if her rank is equal to or greater than $r$.

In the scenario in Table 1, bidder 2, who is a provisional winner, faces a trade-off between bidding and exiting. Suppose bidder 1 will bid with certainty. By exiting, bidder 2 may win at the price $P_{t-1}$ if bidder 3 exits (Case 5), but she will lose if bidder 3 stays in. In contrast, by bidding, bidder 2 may win at the higher price $P_{t}$ if bidder 3 exits (Case 2).

Proposition 2. The LAB auction is inefficient.

There are two sources of inefficiency: discrete bid levels and asymmetric bidding behavior. First, discrete bid levels may prevent bidders from expressing a difference in their valuations. Any auction with discrete bid levels is generally inefficient. As the size of bid increments becomes small, so does the difference between the HRB and LAB pricing rules. The difference in efficiency is smaller as well. Second, although bidders and their bidding strategies are symmetric, asymmetric bidding behavior is introduced by naming and ranking provisional winners as discussed in Lemmas 2 and 3. In some situations, a bidder with a particular valuation bids if she is a provisional loser, but in the same circumstances, she exits if she is a provisional winner. Differential bid shading is exhibited among provisional winners, and bidding above valuation is found among provisional losers. These differences are a separate source of inefficiency. 
Exit bids in the HRB auction overcome both sources of inefficiency of the LAB auction. In the HRB auction, there is no bid shading, and all value differences are expressed.

\section{Equilibrium Characterization with One Item and Two Bidders}

To further characterize equilibrium behavior in the LAB auction, it is necessary to simplify the setting to one item and two bidders (1 and 2). These assumptions are maintained through $\S 8$. Although this setting is limiting, it will provide intuition for cases with more items and more bidders.

With two bidders and a single item, there are two possible ranks: a provisional winner or a provisional loser. Once a bidder knows her rank, she can infer that her opponent's rank is the other. Specifically, for all $t, \mathbf{H}_{1 t}$ is the complement of $\mathbf{H}_{2 t}$ and vice versa. The auction ends when at least one bidder exits. If in round $t$ only one bidder exits, the active bidder receives the item and pays $P_{t}$. If both bidders exit in round $t$, the provisional winner in round $t$ gets the item at a price of $P_{t-1}$.

Definition 1. Bidder $i$ follows a straightforward bidding strategy in round $t$ when

$$
q_{i t}\left(x_{i}\right)= \begin{cases}1 & x_{i} \geq P_{t}, \\ 0 & x_{i}<P_{t} .\end{cases}
$$

LEMMA 4. For a bidder with any rank, bidding above her valuation is a weakly dominated strategy. For a provisional loser, bidding straightforwardly is a weakly dominant strategy.

As discussed in Lemma 2, a provisional loser bids if her valuation is higher than the current clock price. In the one-item case, the final price is at least the current clock price if one or more bids are submitted. In contrast to the case with two or more items, it is not profitable for a bidder with any rank to bid when the current clock price is above her valuation.

The fact that a provisional loser bids straightforwardly greatly simplifies the analysis. To construct an equilibrium, we need to solve for the bidding behavior of a provisional winner. A provisional winner's bidding strategy depends not only on her valuation, but also on the history of the opponent's ranks. For instance, a provisional winner may exit when a ranking history implies that a provisional loser's valuation has a lower bound less than the next clock price. In contrast, a provisional winner will continue to compete when an inferred provisional loser's valuation is higher than the current clock price. This dependence on the history of rankings implies that even with the same realized valuation, different ranking histories may produce different allocations and final prices.

Lemma 5. In any round $t=1,2, \ldots, T-1$, a provisional winner's expected gain from exiting-expected payoff from exiting less expected payoff from bidding-is decreasing in her valuation.

Simply put, a provisional winner's bidding strategy is monotonic in valuation. Intuitively, if an optimal strategy of a provisional winner with valuation $x$ in any round $t$ is bidding (exiting), it is an optimal strategy of a provisional winner with valuation $x^{\prime}>x\left(x^{\prime}<x\right)$ to bid (exit) in round $t$ as well.

Let $\hat{x}_{t}: \Theta_{t} \rightarrow[0,1]$ be a critical valuation for a bidding strategy in round $t$. This function $\hat{x}_{t}\left(\mathbf{H}_{i t}\right)$ indicates that in round $t$, a bidder with a valuation at least $\hat{x}_{t}\left(\mathbf{H}_{i t}\right)$ will bid, and one with valuation less than $\hat{x}_{t}\left(\mathbf{H}_{i t}\right)$ will exit. Moreover, if $P_{t-1}<\hat{x}_{t}\left(\mathbf{H}_{i t}\right)<P_{t}$, $\hat{x}_{t}\left(\mathbf{H}_{i t}\right)$ is a valuation of a bidder who is indifferent between bidding and exiting in round $t$ for a ranking history $\mathbf{H}_{i t}$.

According to Lemma 4, the provisional loser bids straightforwardly regardless of the ranking history. Therefore, for any ranking history $\mathbf{H}_{i t} \in \mathbf{\Theta}_{t}$ such that $R_{i t}=0, \hat{x}_{t}\left(\mathbf{H}_{i t}\right)=P_{t}$.

In each round, a bidder applies Bayesian updating to the lower bound of her opponent's valuation and uses this lower bound to determine an optimal strategy. For example, suppose in round $t$ with bidder 1's ranking history of $\mathbf{H}_{1 t}$, bidder 1 is a provisional loser and bidder 2 is a provisional winner. Suppose both of them have a valuation above $P_{t+1}$ and bid at $P_{t}$. In round $t+1$, bidder 1 is selected as a provisional winner, and she makes an inference that bidder 2's valuation must be in $\left[\hat{x}_{t}\left(\mathbf{H}_{2 t}\right), 1\right]$. If, for instance, $P_{t+1}<$ $\hat{x}_{t}\left(\mathbf{H}_{2 t}\right)<P_{t+2}$, bidder 1 , aware that bidder 2 has a valuation higher than the current clock price and follows a straightforward bidding strategy, will bid in round $t+1$. 
The lower bound is at least the previous clock price because no bidder bids above her valuation according to Lemma 4. It can be higher than the previous clock price when an equilibrium strategy suggests that the critical valuation of the provisional winner is higher than the previous clock price, and she in turn bids. Importantly, being a provisional winner reveals more information on valuation to the opponent than being a provisional loser.

Let $l_{t}\left(\mathbf{H}_{j t}\right) \equiv \max \left\{P_{t-1}, \hat{x}_{t-1}\left(\mathbf{H}_{j, t-1}\right)\right\}$ be an inferred lower bound of bidder $j^{\prime}$ s valuation in round $t$ as a function of a ranking history $\mathbf{H}_{j t}$. Consider a provisional winner $i$ in round $t$ with valuation $x_{i}>P_{t}$. Let $\pi_{i t}\left(q_{i t}, x_{i}, \mathbf{H}_{i t}\right)$ be bidder $i$ 's expected payoffs in round $t$ when submitting a decision $q_{i t} \in\{0,1\}$ given a ranking history $\mathbf{H}_{i t}$, where 0 and 1 correspond to exiting and bidding, respectively. If $l_{t}\left(\mathbf{H}_{j t}\right) \geq P_{t}$, a provisional winner's dominant strategy is bidding if $x_{i} \geq P_{t}$ and exiting otherwise. Next, consider the case where $l_{t}\left(\mathbf{H}_{j t}\right) \in\left[P_{t-1}, P_{t}\right)$. Let $\Pi_{i, t+1}$ be bidder i's expected payoff in round $t+1$ if the auction proceeds to round $t+1$. Bidder $i$ 's payoffs of bidding and exiting in round $t$ are, respectively,

$$
\begin{gathered}
\pi_{i t}\left(q_{i t}=1, x_{i}, \mathbf{H}_{i t}\right) \equiv\left(x_{i}-P_{t}\right) \frac{F\left(P_{t}\right)-F\left(l_{t}\left(\mathbf{H}_{j t}\right)\right)}{1-F\left(l_{t}\left(\mathbf{H}_{j t}\right)\right)}+\Pi_{i, t+1}, \\
\pi_{i t}\left(q_{i t}=0, x_{i}, \mathbf{H}_{i t}\right) \equiv\left(x_{i}-P_{t-1}\right) \frac{F\left(P_{t}\right)-F\left(l_{t}\left(\mathbf{H}_{j t}\right)\right)}{1-F\left(l_{t}\left(\mathbf{H}_{j t}\right)\right)} .
\end{gathered}
$$

It is an optimal strategy to bid if $\pi_{i t}\left(q_{i t}=\right.$ $\left.1, x_{i}, \mathbf{H}_{i t}\right) \geq \pi_{i t}\left(q_{i t}=0, x_{i}, \mathbf{H}_{i t}\right)$ and exit if $\pi_{i t}\left(q_{i t}=\right.$ $\left.1, x_{i}, \mathbf{H}_{i t}\right)<\pi_{i t}\left(q_{i t}=0, x_{i}, \mathbf{H}_{i t}\right)$. The value of $\hat{x}_{t}\left(\mathbf{H}_{i t}\right)$ can be either equal to a clock price or between two consecutive clock prices. It is equal to a clock price, say $P_{s}$ for $s \geq t$, if $\pi_{i t}\left(q_{i t}=1, P_{s}, \mathbf{H}_{i t}\right) \geq \pi_{i t}\left(q_{i t}=0, P_{s}, \mathbf{H}_{i t}\right)$ and $\pi_{i t}\left(q_{i t}=1, P_{s}-\varepsilon, \mathbf{H}_{i t}\right)<\pi_{i t}\left(q_{i t}=0, P_{s}-\varepsilon, \mathbf{H}_{i t}\right)$, where $\varepsilon$ is a small positive number. The value of $\hat{x}_{t}\left(\mathbf{H}_{i t}\right)$ will be between $P_{s}$ and $P_{s+1}$ if $\pi_{i t}\left(q_{i t}=1, \hat{x}_{t}\left(\mathbf{H}_{i t}\right), \mathbf{H}_{i t}\right)=$ $\pi_{i t}\left(q_{i t}=0, \hat{x}_{t}\left(\mathbf{H}_{i t}\right), \mathbf{H}_{i t}\right)$ and $\hat{x}_{t}\left(\mathbf{H}_{i t}\right) \in\left(P_{s}, P_{s+1}\right)$. We assign $\hat{x}_{t}\left(\mathbf{H}_{i t}\right)=\infty$ if it is optimal for a provisional winner with any valuation to exit, regardless of the ranking history. Obviously, $\hat{x}_{T-1}\left(\mathbf{H}_{i, T-1}\right)=\infty$ for any $\mathbf{H}_{i, T-1} \in \mathbf{\Theta}_{T-1}$.

Proposition 3. An equilibrium of a discrete clock auction with $L A B$ is characterized by $\hat{x}_{t}\left(\mathbf{H}_{i t}\right)$ for any $\mathbf{H}_{i t} \in$ $\Theta_{t}$ and for $t=1,2, \ldots, T-1$. In round $t$ with a ranking history $\mathbf{H}_{i t} \in \mathbf{\Theta}_{t}$, bidder $i$ bids if her valuation is in $\left[\hat{x}_{t}\left(\mathbf{H}_{i t}\right), 1\right]$ and exits if her valuation is in $\left[0, \hat{x}_{t}\left(\mathbf{H}_{i t}\right)\right)$.
Figure 1 Strategy of a Provisional Winner with Valuation $x \in\left[P_{t}, P_{t+1}\right)$

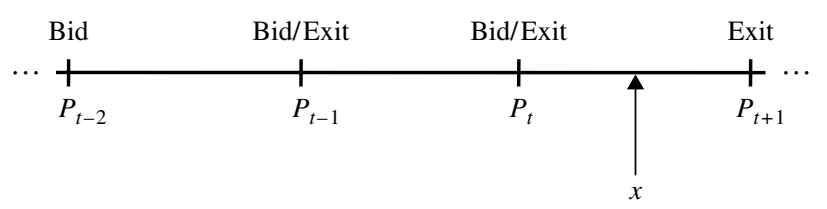

\section{Equilibrium Characterization with a Fixed Bid Increment and Uniform Valuations}

To further characterize equilibrium behavior, it is helpful to assume a fixed bid increment and assume that valuations are uniformly distributed on $[0,1]$. Thus, $\Delta_{t}=\Delta=1 /(T-1)$ for all $t$ and $F(x)=x$. We maintain these assumptions through $\S 8$.

LEMMA 6. In any round $t \leq s-2$ with a ranking history $\mathbf{H}_{i t} \in \mathbf{\Theta}_{t}$, a provisional winner in round $t$ with a valuation $x \in\left[P_{s}, P_{s+1}\right)$ always bids.

Assuming fixed bid increments and uniform valuations greatly simplifies the equilibrium derivation, because we only need to solve for the provisional winner's bidding behaviors in the two rounds below her valuation. Figure 1 summarizes the strategy of a bidder with valuation $x \in\left[P_{t}, P_{t+1}\right)$ when she is a provisional winner. According to Lemma 6 , if she is a provisional winner in any round 1 to $t-2$, she will bid. She may bid or exit if she is a provisional winner in round $t-1$ or $t$ depending on her valuation and ranking history. By Lemma 4 , she will exit in round $t+1$ regardless.

Proposition 4. Inefficiency in the $L A B$ auction can be reduced by smaller bid increments.

In this setting, efficiency suffers from discrete bid levels and differential bid shading. However, according to Lemma 6, the amount of bid shading is limited to only two bid levels. Therefore, smaller bid increments reduce the absolute amount of bid shading as well as constraints on expressing value differences.

\section{An Example with Four Bid Levels}

To get a better sense of the equilibrium, consider an example with two bidders, one item, and four bid levels: $\mathbf{P}=(0,1 / 3,2 / 3,1)$ or $\Delta=1 / 3$. Solving for an equilibrium yields a provisional winner's critical valuations, $\hat{x}_{1}(1)=P_{2}+(2 / 5) \Delta=4 / 5, \hat{x}_{2}(0,1)=2 / 3$, 
Table 2 Valuations of a Provisional Winner Whose Optimal Strategy Is Bidding in Each Round and Ranking History

\begin{tabular}{lccc}
\hline Round & Price & Ranking history & Valuation \\
\hline 1 & $1 / 3$ & $(1)$ & {$[4 / 5,1]$} \\
2 & $2 / 3$ & $(1,1)$ & None \\
& & $(0,1)$ & {$[2 / 3,1]$} \\
3 & 1 & Any & None \\
\hline
\end{tabular}

$\hat{x}_{2}(1,1)=\infty$, and $\hat{x}_{3}\left(\mathbf{H}_{i 3}\right)=\infty$ for any $\mathbf{H}_{i 3} \in \mathbf{\Theta}_{3}$. The bidding strategy of the provisional winner is summarized in Table 2.

A bidder never bids above her valuation. In round 1 , if a provisional winner has a valuation less than $4 / 5$, she will exit. To show how the ranking history affects inference of the lower bound of an opponent's valuation and bidding behavior, consider bidder 1 with valuation $x_{1}$ and bidder 2 with valuation $x_{2}$, where $x_{1}>x_{2} \geq 4 / 5$. Suppose she is a provisional winner in round 2 . If the ranking history is $\mathbf{H}_{12}=(0,1)$, the fact that bidder 2 bids in round 1 implies that her valuation is higher than $4 / 5$, and thus she will bid in round 2. Because bidder 1 knows that bidder 2 will bid and her valuation is above the current clock price as well, it is a dominant strategy to bid. In contrast, if the ranking history is $\mathbf{H}_{12}=(1,1)$, bidder 1 infers that bidder 2's valuation is higher than $1 / 3$. Bidder 1 thus exits and loses. Bidder 1 would have done better if the ranking history had been $(0,1)$. The allocation in this case is inefficient.

This example shows that being a provisional loser provides a bidder a chance to learn about her opponent's valuation and that a ranking history affects a provisional winner's bidding strategy. It is this history dependence that makes the equilibrium calculation so difficult. With four bid levels, the expected revenue is 0.278 , which is lower than that of the HRB auction, which is equal to $1 / 3$.

\section{Expected Revenue with Profit-Maximizing Bidders}

In this section, we continue to assume that there is a single item and two bidders whose valuations are uniformly distributed on $[0,1]$. There are $T$ bid levels, equally spaced. Because all bidders bid truthfully in the HRB auction, the expected revenue is $R_{\mathrm{HRB}}=1 / 3$.
Calculating an expected revenue of the LAB auction is tedious because all possible histories and associated outcomes have to be considered. Thus, the problem grows exponentially in the number of bid levels, making derivation of an equilibrium with an arbitrary number of bid levels impossible. We can, however, calculate expected revenue for small $T$. We also can calculate revenue in the limit as the number of bid levels goes to infinity (bid increments become small). The limit result comes from the limit of upper and lower bounds on revenue. Because both limits converge to the same thing, the equilibrium expected revenue must converge as well.

Lemma 7. Suppose all bidders follow the straightforward strategy. For $T \geq 3$, the expected revenue is given by

$$
R_{\mathrm{LAB}}^{\mathrm{SB}}(T)=\frac{(T-2)(2 T+3)}{6(T-1)^{2}} .
$$

In addition, $\lim _{T \rightarrow \infty} R_{\mathrm{LAB}}^{\mathrm{SB}}(T)=R_{\mathrm{HRB}}$.

A rational bidder infers a lower bound of her opponent's valuation from a ranking history and a previous clock price. The inferred opponent's valuation is at the previous clock price unless a ranking history implies that it is higher. The higher the lower bound, the less the bid shading. Consider a maximum shading strategy-in every round, a provisional winner infers that a lower bound of the provisional loser's valuation is a previous clock price. Therefore, the lowest inference of lower bound that leads to the highest amount of shading constitutes the maximum shading strategy, as the name suggests. Explicitly, consider a bidder with valuation $x_{t} \in\left[P_{t}, P_{t+1}\right)$, where $t \geq 2$. In any round $s \leq t-2$, she will bid regardless of her ranking according to Lemma 6 . In round $t$, if she is a provisional winner, she will exit because

$$
\begin{aligned}
\pi_{i t}\left(q_{i t}=1, x_{i}, \mathbf{H}_{i t}\right) \equiv & \left(x_{i}-P_{t}\right) \frac{\Delta}{1-F\left(P_{t-1}\right)} \\
& +\frac{1}{2}\left(x_{i}-P_{t}\right) \frac{\Delta}{1-F\left(P_{t-1}\right)} \\
< & \left(x_{i}-P_{t-1}\right) \frac{\Delta}{1-F\left(P_{t-1}\right)} \\
\equiv & \pi_{i t}\left(q_{i t}=0, x_{i}, \mathbf{H}_{i t}\right) .
\end{aligned}
$$

Given that she will exit in round $t$, in round $t-1$ we can calculate that $\hat{x}_{t-1}\left(\mathbf{H}_{i, t-1}\right)=P_{t}+(2 / 5) \Delta$. 
Lemma 8. Suppose a provisional winner follows the maximum shading strategy and a provisional loser follows a straightforward bidding strategy. For $T \geq 5$, the expected revenue is given by

$$
R_{\mathrm{LAB}}^{\mathrm{MS}}(T)=\frac{T^{3}-195 T^{2}+397 T-549}{150(T-1)^{3}} .
$$

In addition, $\lim _{T \rightarrow \infty} R_{\mathrm{LAB}}^{\mathrm{MS}}(T)=R_{\mathrm{HRB}}$.

Proposition 5. The expected revenue of the $L A B$ auction converges to that of an HRB auction as bid increments become small —as the number of bid levels goes to infinity.

The expected revenue of the LAB auction when bidders follow a straightforward bidding strategy is an upper bound and the expected revenue of the LAB auction when a provisional winner follows a maximum shading strategy is a lower bound of the expected revenue of the $\mathrm{LAB}$ auction with profitmaximizing bidders. Because the upper and lower bounds converge to $1 / 3$, the expected revenue of the $\mathrm{LAB}$ auction converges to $1 / 3$ as well.

With profit-maximizing bidders, the expected revenues of the LAB auction with four to seven bid levels are as follows.

\begin{tabular}{lccccc}
\hline$T$ & 4 & 5 & 6 & 7 & $\infty$ \\
\hline Expected revenue & 0.278 & 0.301 & 0.311 & 0.317 & 0.333 \\
\hline
\end{tabular}

We see that the expected revenue is increasing in the number of bid levels at a decreasing rate. We conjecture that the LAB auction always yields lower expected revenue than the HRB auction.

\section{Extension to Bidders with an Anticipated Loser's Regret at Profitable Prices}

In this section, we extend the model to include the possibility that bidders' anticipated regret of losing at profitable prices will cause them to bid more aggressively than under pure profit maximization. Again we consider the case with two bidders and a single item. Valuations are uniformly distributed on $[0,1]$ with $T$ equally spaced bid levels.

There is strong support for this view in sealed-bid, first-price auctions (Engelbrecht-Wiggans and Katok 2007, 2008; Filiz-Ozbay and Ozbay 2007; Delgado et al. 2008). It seems plausible that the same behavioral bias-caring more about the negative emotion coming from losing at profitable prices than the positive emotion of extra profit from successful bid shading-may exist in the dynamic context. In a separate paper, we examine this possibility in the experimental laboratory (Cramton et al. 2009). Here, we present the basic theory.

The behavioral theory posits that bidders systematically put too much weight on profits lost from losing at profitable prices and too little weight on profits gained from successful bid shading. In our context, it is the bids of a provisional winner that are affected by this asymmetric treatment of profits, because only the provisional winner has an incentive to bid below her valuation.

Define $\tilde{\pi}_{i t}\left(q_{i t}, q_{j t}, R_{i t}\right)$ as bidder $i$ 's payoff if the auction ends given that bidder $i$ submits $q_{i t}$, bidder $j$ submits $q_{j t}$, and $R_{i t}$ is bidder $i$ 's rank in round $t$. Recognizing anticipated loser's regret, we define bidder $i$ 's payoff function as

$$
\begin{aligned}
& \tilde{\pi}_{i t}\left(q_{i t}=1, q_{j t}=0, R_{i t}=1\right)=x_{i}-P_{t}, \\
& \tilde{\pi}_{i t}\left(q_{i t}=0, q_{j t}=1, R_{i t}=1\right) \\
& \quad=-\alpha \max \left\{0, E_{t}\left[\tilde{\pi}_{i, t+1}\left(q_{i t}=1, q_{j t}=1, R_{i t}=1\right)\right]\right\}, \\
& \tilde{\pi}_{i t}\left(q_{i t}=0, q_{j t}=0, R_{i t}=1\right)=x_{i}-P_{t-1}, \\
& \tilde{\pi}_{i t}\left(q_{i t}=1, q_{j t}=0, R_{i t}=0\right)=x_{i}-P_{t}, \\
& \tilde{\pi}_{i t}\left(q_{i t}=0, q_{j t}=1, R_{i t}=0\right) \\
& \quad=-\alpha \max \left\{0, E_{t}\left[\tilde{\pi}_{i, t+1}\left(q_{i t}=1, q_{j t}=1, R_{i t}=0\right)\right]\right\}, \\
& \tilde{\pi}_{i t}\left(q_{i t}=0, q_{j t}=0, R_{i t}=0\right) \\
& \quad=-\alpha \max \left\{0, E_{t}\left[\tilde{\pi}_{i, t+1}\left(q_{i t}=1, q_{j t}=0, R_{i t}=0\right)\right]\right\},
\end{aligned}
$$

where $\alpha$ is the regret coefficient indicating the strength of anticipated regret. In this section, assume that $0 \leq$ $\alpha<1$.

Given this payoff structure, it is still a weakly dominant strategy for a provisional loser to bid straightforwardly. Consider a provisional loser with a valuation between $P_{t}$ and $P_{t+1}$. In round $t+1$, she could win only at an unprofitable price by bidding. Hence, she does not have regret, so she exits. Therefore, it is a weakly dominated strategy to bid above her valuation. Moreover, exiting below her valuation is still a weakly dominated strategy because doing so 
Figure 2 Relationship Between the Critical Regret Coefficient and the Number of Bid Levels

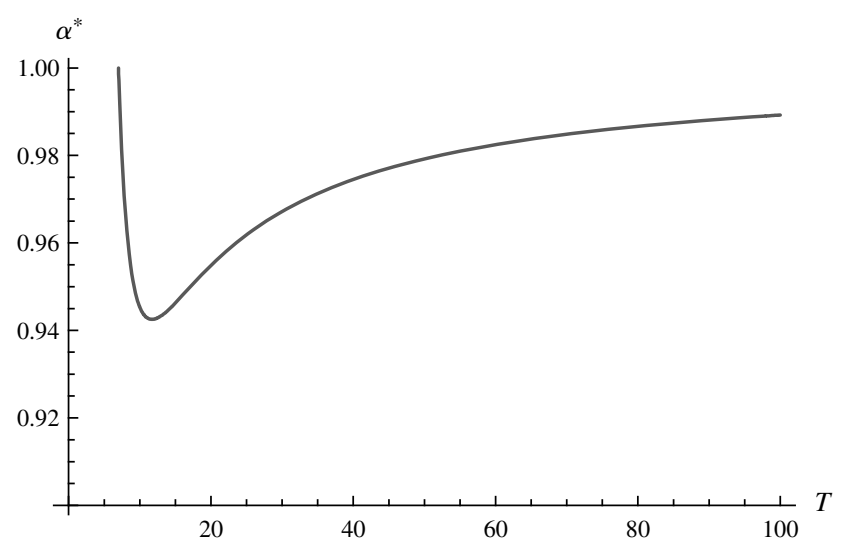

penalizes the bidder even more than in the no-regret case, resulting in a negative expected payoff, whereas bidding yields a positive expected payoff.

For a provisional winner who faces a trade-off between exiting and bidding, exiting is now less attractive because she anticipates that she will regret if losing. A provisional winner is expected to bid more aggressively when anticipated regret is more intense.

LemMa 9. Suppose a provisional winner follows the maximum shading strategy and a provisional loser follows the straightforward bidding strategy. For $T \geq 5$ and $0 \leq$ $\alpha<1$, the expected revenue is given by

$$
\begin{aligned}
\tilde{R}_{\mathrm{LAB}}^{\mathrm{MS}}(T, \alpha)= & \frac{1}{150(1+\alpha)^{2}(T-1)^{3}} \\
& \cdot\left(50 T^{3}-195 T^{2}+397 T-549\right. \\
& +2 \alpha\left(50 T^{3}-150 T^{2}+163 T-171\right) \\
& \left.+\alpha^{2}\left(50 T^{3}-105 T^{2}-23 T-9\right)\right) .
\end{aligned}
$$

In addition, $\lim _{T \rightarrow \infty} \tilde{R}_{\mathrm{LAB}}^{\mathrm{MS}}(T, \alpha)=R_{\mathrm{HRB}}$.

As in the no-regret case, $\tilde{R}_{\mathrm{LAB}}^{\mathrm{MS}}(T, \alpha)$ is a lower bound of the expected revenue of the LAB auction with fear of losing. The upper bound is the same as the no-regret case in Lemma 7. Therefore, the expected revenue of the LAB auction with fear of losing converges to $1 / 3$.

Nonetheless, in the interesting case of finite $T$ as in any real auction, if the regret coefficient is sufficiently large, the LAB auction yields higher expected revenue than the HRB auction. The necessary condition is given in Proposition 6.
Proposition 6. Suppose a provisional winner follows the maximum shading strategy and a provisional loser follows the straightforward bidding strategy. If $T \geq 7$ and

$$
\begin{aligned}
& \frac{1}{45 T^{2}-173 T+41}(121-13 T \\
& \left.\quad+5\left(81 T^{4}-756 T^{3}+2688 T^{2}-3984 T+1404\right)^{1 / 2}\right) \\
& \leq \alpha<1
\end{aligned}
$$

then $\tilde{R}_{\mathrm{LAB}}^{\mathrm{MS}}(T, \alpha) \geq R_{\mathrm{HRB}}$.

Define $\alpha^{*}$ as the critical regret coefficient such that $\tilde{R}_{\mathrm{LAB}}^{\mathrm{MS}}\left(T, \alpha^{*}\right)=R_{\mathrm{HRB}}$. Figure 2 shows the relationship between the critical regret coefficient and the number of bid levels. With six bid levels, a regret coefficient of one guarantees that the LAB auction yields higher revenue than the HRB auction. If $T \geq 7$ and $\alpha$ is sufficiently close to one, we can be certain that the expected revenue of the LAB auction is higher. In $\S 8$, we show that the actual regret coefficient (as opposed to the critical regret coefficient $\alpha^{*}$ ) with six bid levels that makes the LAB and HRB auctions have equal revenues is 0.66 , not 1 .

\section{An Example with Four and Six Bid Levels and Fear of Losing}

By using a similar solution technique as used in $\S 5$, we can explicitly calculate a perfect Bayesian equilibrium with fear of losing for a small number of bid

\begin{tabular}{lccc} 
Table 3 & \multicolumn{2}{c}{$\begin{array}{l}\text { Valuation of a Provisional Winner Whose Optimal Strategy Is } \\
\text { Bidding in Each Round and Ranking History When } 0 \leq \alpha<1\end{array}$} \\
\hline Round & Price & Ranking history & Valuation \\
\hline 1 & $1 / 3$ & $(1)$ & {$\left[\begin{array}{c}2 / 3+\frac{2(1-\alpha)}{15(1+\alpha)}, 1 \\
\end{array}\right.$} \\
2 & $2 / 3$ & $(1,1)$ & None \\
3 & 1 & $(0,1)$ & None \\
\hline
\end{tabular}

Table 4 Valuation of a Provisional Winner Whose Optimal Strategy Is Bidding in Each Round and Ranking History When $\alpha \geq 1$

\begin{tabular}{lccc}
\hline Round & Price & Ranking history & Valuation \\
\hline 1 & $1 / 3$ & $(1)$ & {$\left[1 / 3+\frac{2}{3(1+\alpha)}, 1\right]$} \\
2 & $2 / 3$ & $(1,1)$ & None \\
3 & 1 & $(0,1)$ & {$[2 / 3,1]$} \\
& Any & None \\
\hline
\end{tabular}


Figure 3 Expected Revenue of the LAB Auction with Fear of Losing, $T=4$ and $T=6$

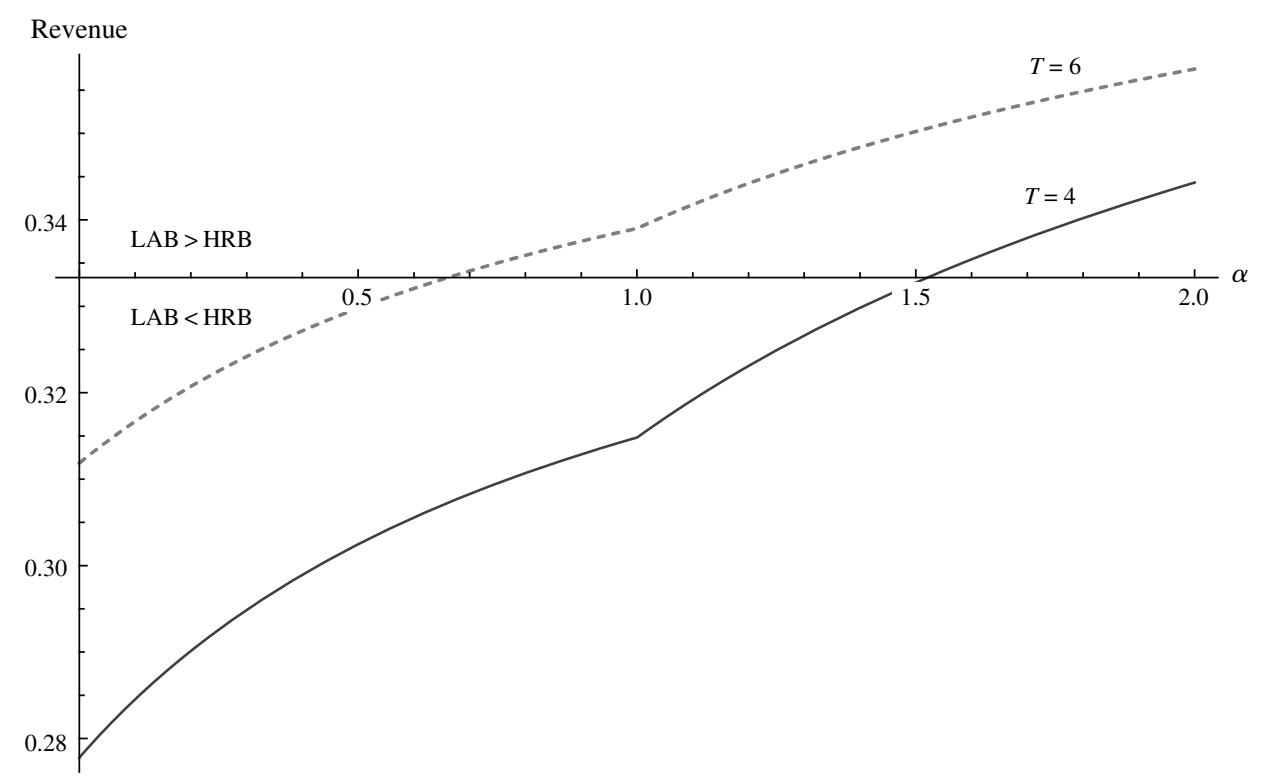

levels. Consider the case of four bid levels. A provisional winner's bidding strategies when $0 \leq \alpha<1$ and $\alpha \geq 1$ are as shown in Tables 3 and 4 , respectively.

The equilibrium strategy with $\alpha<1$ is similar to the no-regret case, but the critical valuation is instead a function of the regret coefficient. Moreover, in round 1 , a provisional winner with any valuation below $2 / 3$ exits if $\alpha<1$, but if $\alpha \geq 1$, a provisional winner with valuation close to $2 / 3$ may bid. In both cases, the larger the regret coefficient, the lesser the amount of shading and the higher the expected revenue. Expected revenues when $\alpha<1$ and $\alpha \geq 1$ are

$$
\tilde{R}_{\mathrm{LAB}}(4, \alpha)= \begin{cases}\frac{15+19 \alpha}{54(1+\alpha)} & \alpha<1, \\ \frac{11 \alpha^{3}+27 \alpha^{2}+25 \alpha+5}{27(1+\alpha)^{3}} & \alpha \geq 1 .\end{cases}
$$

Similar calculations can be done for the case of six bid levels. Figure 3 plots the expected revenue from the LAB auction with $T=4$ (solid) and $T=6$ (dashed) as a function of the regret coefficient. Revenue increases with the fear of losing, and exceeds the revenue of $1 / 3$ from the HRB auction if the fear of losing is sufficiently strong. The $x$-axis is drawn at $1 / 3$, so points above the axis are instances where the LAB auction yields higher revenues than the HRB auction. With four bid levels, the LAB auction yields higher expected revenue than the HRB auction if $\alpha>$ 1.52; with six bid levels, the LAB auction yields higher expected revenue than the HBR auction if $\alpha>0.66$. Because six or more bid levels is typical in practice, we conclude that the LAB auction may yield higher revenues than the HRB auction with plausible levels of fear of losing.

\section{Lowest Accepted Bid with Exit Bids}

Our version of lowest accepted bid is motivated from India's 3G auction. A variation which may be preferable is the lowest accepted bid with exit bids (LABx). This is identical to HRB in that exit bids are allowed, but the price is set by the lowest accepted bid, so there is a first-price incentive to shade one's bid. ${ }^{1}$

Assume that there are $N$ bidders whose valuations are distributed on the interval $[0,1]$ with the distribution function $F$. If there is excess demand in any round, the auction proceeds to the next round. If a bidder exits in round $t$, the bidder can submit an exit bid-a price between $P_{t-1}$ and $P_{t}$. The final price is

\footnotetext{
${ }^{1}$ Another variation is the pricing rule analyzed in Rothkopf and Harstad (1994) and David et al. (2007). Such a pricing rule is dominated in both revenue and efficiency by highest rejected bid with exit bids, regardless of whether bidders fear losing.
} 
determined by the lowest accepted exit bid. That is, in round $t$ such that $Q_{t}=K$, the auction ends and the final price is $P_{t}$, and the items are awarded to active bidders. If $Q_{t}<K$, the $\left(K-Q_{t}\right)$-highest exit bid determines the final price, and the items are awarded to the $Q_{t}$ active bidders and exiting bidders with the highest $K-Q_{t}$ exit bids.

Let $\mathbf{M}_{t}=\left(M_{1}, M_{2}, \ldots, M_{t}\right)$ be a vector indicating the number of active bidders from round 1 to round $t$, where $M_{t} \in\{2, \ldots, N\}$ is the number of active bidders in round $t$, and $M_{1} \geq M_{2} \geq \cdots \geq M_{t}$. Let $\boldsymbol{\Omega}_{t}=$ $\left\{\mathbf{M}_{t} \mid M_{t} \in\{2, \ldots, N\}, M_{1} \geq M_{2} \geq \cdots \geq M_{t}\right\}$ be the set of all possible active bidder histories from round 1 to round $t$. Assume that the active bidder history $\mathbf{M}_{t}$ is common knowledge.

Given the history, the bidder forms a belief of a lower bound of active bidders' valuations and chooses whether to bid or submit an exit bid accordingly. Because it is a dominated strategy to bid above one's valuation, the lower bound is at least the previous clock price.

Let $x_{t}^{*}:[0, \infty) \times \boldsymbol{\Omega}_{t} \rightarrow[0,1]$ be an intermediate valuation in round $t$ given a regret coefficient and active bidder history. Let $B_{t}:[0,1] \times[0, \infty) \times \boldsymbol{\Omega}_{t} \rightarrow\left[P_{t-1}, P_{t}\right)$ be an equilibrium exit bid function in round $t$ given a valuation, regret coefficient, and a history of the number of active bidders. An equilibrium bidding strategy is defined by these two functions. That is, a bidder with valuation $x \in\left[x_{t-1}^{*}\left(\alpha, \mathbf{M}_{t-1}\right), x_{t}^{*}\left(\alpha, \mathbf{M}_{t}\right)\right)$ exits in round $t$ and submits an exit bid $B_{t}\left(x, \alpha, \mathbf{M}_{t}\right)$. The equilibrium bidding strategy is illustrated in Figure 4.

Both $x_{t}^{*}\left(\alpha, \mathbf{M}_{t}\right)$ and $B_{t}\left(x, \alpha, \mathbf{M}_{t}\right)$ can be derived iteratively from round 1 to round $T$. In any round $t$ and any $\mathbf{M}_{t} \in \boldsymbol{\Theta}_{t}$, bidders infer that their opponents' valuations are in $\left[x_{t-1}^{*}\left(\alpha, \mathbf{M}_{t-1}\right), 1\right]$. The exit bid function is

$$
\tilde{B}_{t}\left(x, \alpha, z_{t}, M_{t}\right)=\frac{1}{G\left(s \mid z_{t}\right)^{1-\alpha}} \int_{z_{t}}^{x} s d G\left(s \mid z_{t}\right)^{1-\alpha},
$$

\section{Figure 4 Equilibrium Bidding Strategy in the LABx Auction}

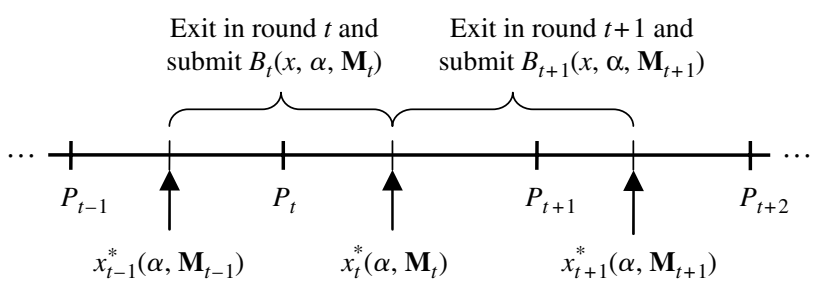

where $z_{t}=x_{t-1}^{*}\left(\alpha, \mathbf{M}_{t-1}\right)$ and $G\left(s \mid z_{t}\right)=F\left(s \mid z_{t}\right)^{M_{t}-1}$. The equation $x_{t}^{*}\left(\alpha, \mathbf{M}_{t}\right) \equiv x^{*}$ can be obtained by solving the condition $\tilde{B}_{t}\left(x^{*}, \alpha, x_{t-1}^{*}\left(\alpha, \mathbf{M}_{t-1}\right), M_{t}\right)=P_{t}$ for $x^{*}$. Note that the equilibrium exit bid function can be rewritten as $B_{t}\left(x, \alpha, \mathbf{M}_{t}\right) \equiv \tilde{B}_{t}\left(x, \alpha, x_{t-1}^{*}\left(\alpha, \mathbf{M}_{t-1}\right), M_{t}\right)$.

Proposition 7. A symmetric equilibrium is characterized by $x_{t}^{*}\left(\alpha, \mathbf{M}_{t}\right)$ and $B_{t}\left(x, \alpha, \mathbf{M}_{t}\right)$ for $t=1,2, \ldots, T-1$ and for any $\mathbf{M}_{t} \in \boldsymbol{\Omega}_{t}$. Define $x_{0}^{*}(\alpha, \varnothing)=0$. In round $t$ with a history $\mathbf{M}_{t} \in \mathbf{\Omega}_{t}$, a bidder with valuation $x \in$ $\left[x_{t-1}^{*}\left(\alpha, \mathbf{M}_{t-1}\right), x_{t}^{*}\left(\alpha, \mathbf{M}_{t}\right)\right)$ exits in round $t$ and submits an exit bid equal to $B_{t}\left(x, \alpha, \mathbf{M}_{t}\right)$. For $t=1,2, \ldots, T-1$ and for any $\mathbf{M}_{t} \in \mathbf{\Omega}_{t}, x_{t}^{*}\left(\alpha, \mathbf{M}_{t}\right)$ is decreasing in $\alpha$, and $B_{t}\left(x, \alpha, \mathbf{M}_{t}\right)$ is increasing in $x$ and $\alpha$.

\section{Proposition 8. The LABx auction is efficient.}

Because the bidding strategy is monotonic in valuation and symmetric, the allocation is efficient. The use of exit bids overcomes both the inefficiency arising from discrete bid levels and the asymmetry created by ranking.

Proposition 9. Revenue equivalence between $H R B$ and $L A B x$ auctions holds if $\alpha=0$. If $\alpha>0$, the $L A B x$ auction yields higher revenue than the HRB auction.

Because the allocation rules and expected payoffs of the lowest-valuation bidder of the HRB and LABx auctions are the same, revenue equivalence immediately follows when $\alpha=0$. In contrast to the HRB auction, in the LABx auction, bidders submit exit bids below their valuations so that fear of losing at a profitable price impacts the bidding strategy in the LABx auction. Similar to the first-price auction, this fear of losing reduces the amount of shading, resulting in higher exit bids relative to the $\alpha=0$ case, and thus implying higher expected revenue.

\section{An Example of the LABx Auction with Four Bid Levels and Fear of Losing}

Assume that there are two bidders and each bidder's valuation is uniformly distributed over an interval $[0,1]$. In the two-bidder case, an active bidder history is irrelevant because the auction ends when any bidder exits. The equilibrium bidding strategy is given in Table 5. 
Table 5 Bidding Strategy of the LABx Auction with Four Bid Levels and Fear of Losing

\begin{tabular}{lcc}
\hline Valuation & Exit round & Exit bid \\
\hline$\left[0, \frac{2+\alpha}{3(1+\alpha)}\right)$ & 1 & $\frac{1+\alpha}{2+\alpha} x$ \\
{$\left[\frac{2+\alpha}{3(1+\alpha)}, \frac{(2+\alpha)(1+2 \alpha)}{3(1+\alpha)^{2}}\right)$} & 2 & $\frac{1}{3(1+\alpha)}+\frac{1+\alpha}{2+\alpha} x$ \\
{$\left[\frac{(2+\alpha)(1+2 \alpha)}{3(1+\alpha)^{2}}, 1\right]$} & 3 & $\frac{1+2 \alpha}{3(1+\alpha)}+\frac{1+\alpha}{2+\alpha} x$
\end{tabular}

If $\alpha=0$ and both bidders bid in round 1 , it implies that both bidders have valuations in $[2 / 3,1]$, and thus no bidder exits in round 2 . The expected revenue when $\alpha>0$ is given as follows:

$$
\begin{aligned}
& \tilde{R}_{\mathrm{LABx}}(4, \alpha) \\
& =\frac{13 \alpha^{7}+98 \alpha^{6}+314 \alpha^{5}+553 \alpha^{4}+580 \alpha^{3}+361 \alpha^{2}+124 \alpha+18}{27(2+\alpha)(1+\alpha)^{6}} .
\end{aligned}
$$

Expected revenues of the $\mathrm{LAB}$ and LABx auctions with fear of losing with four and six bid levels are shown in Figure 5. As the number of bid levels increases, the expected revenue when $\alpha>0$ decreases. This is because LABx converges to HRB as the number of bid levels goes to infinity. The LABx auction achieves maximum revenues when the number of bid levels is set to two; that is, the first-price sealed-bid auction achieves the maximum revenues when bidders fear losing.

\section{Conclusion}

The pricing rule is of fundamental importance in practical auction design. It is now well understood that the pricing rule impacts both the efficiency and the revenues of the auction. Although there is an immense literature on the pricing rule in static (sealed-bid) auctions (first price versus second price in single-unit auctions, and pay as bid versus uniform price in multiunit auctions) little is known about alternative pricing rules in dynamic auctions. This paper begins to fill that gap.

We find that the highest-rejected-bid auction with exit bids is superior in both efficiency and revenues to the lowest-accepted-bid auction with provisional winners when bidders seek to maximize profits. Given this, it may seem odd that India, with a stated objective of revenue maximization, chose the LAB auction.

Behavioral economics provides a plausible explanation for the choice. With the LAB auction, profitmaximizing bidders engage in bid shading and therefore face the risk of losing at profitable prices.

Figure 5 Expected Revenue of the LAB and LABx Auctions with Fear of Losing, $T=4$ and $T=6$

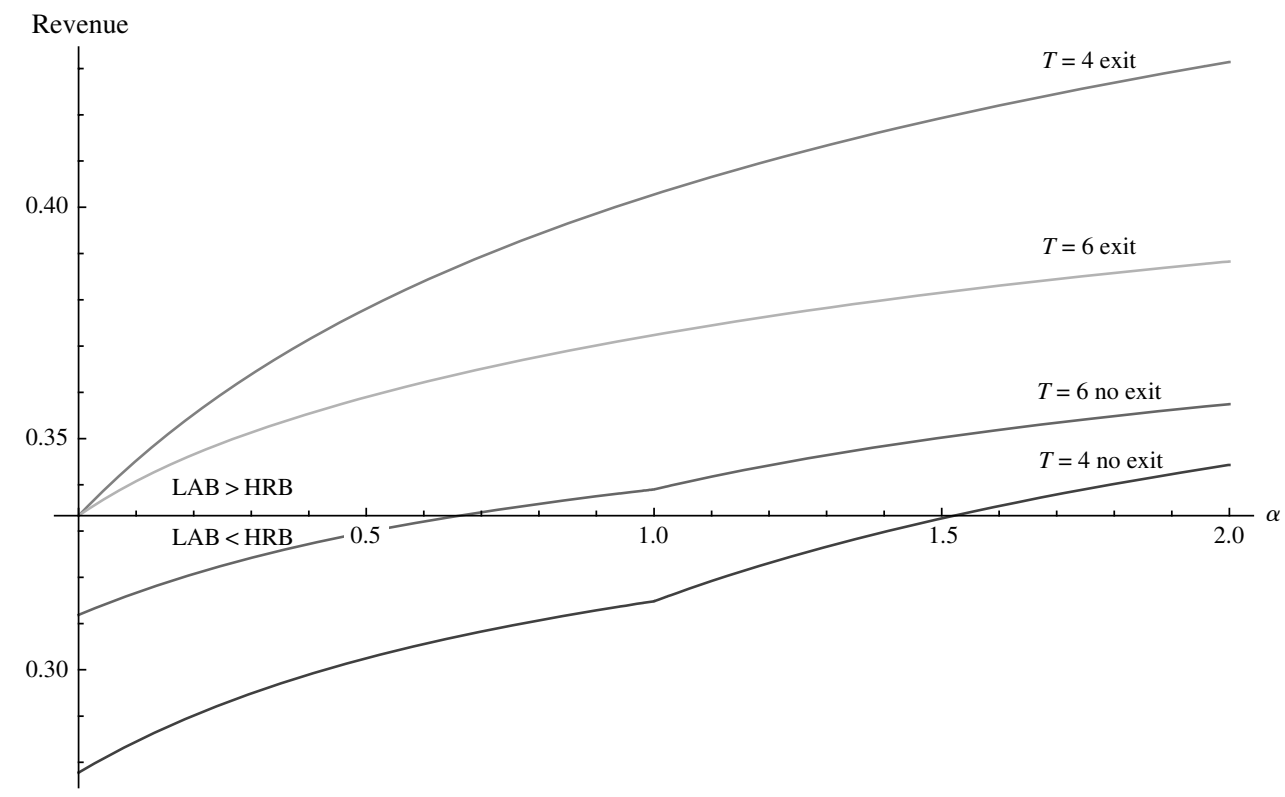


Bidders who fear losing at profitable prices reduce their bid shading to lessen this risk. Provided the fear of losing is sufficiently strong, the LAB auction revenues exceed those of the HRB auction. Thus, the LAB auction may achieve India's primary objective of maximizing revenues. However, the LABx is strictly superior to LAB in all cases in both revenue and efficiency. The use of exit bids eliminates both sources of inefficiency in the LAB auction-discrete bid levels and asymmetric bidding strategies caused by provisional winners.

In Cramton et al. (2009), we conducted laboratory experiments to test the theory. The experiments confirm bidding behavior consistent with a significant loser's regret coefficient. Both the LAB and LABx auctions achieve significantly higher revenues than the HRB auction. Consistent with the theory, bidders in the HRB auction tend to bid true values, and the efficiency and revenue are as predicted by the theory. With LAB and LABx auctions, the bidders engage in much less bid shading than is seen in the standard theory without a fear of losing. This accounts for the significantly higher revenues under the lowestaccepted-bid pricing rule.

Despite the possibility of higher revenues from the LAB format, we would recommend against its use in India or elsewhere. If there are revenue gains, the gains likely are modest (and tightly bounded as we have shown). Offsetting these potential revenue gains are inefficiencies. One source of inefficiency, which we have ignored so far, is bidder participation costs. As we have seen, bidding strategy in the LAB auction is incredibly complex, even in the simplest cases. In sharp contrast, bidding strategy in the HRB auction is simple in simple settings: a bidder of modest size and with additive values across regions, which is often a good first approximation, can bid straightforwardly, raising the bid on each region until the bidder's value is reached. The great complexity of bidding strategy under the LAB format is an important reason to favor the strategically simpler and more efficient HRB format.

Our view is that India would be better off in the long run if it focused on efficient auctions. Efficient auctions are much simpler for bidders and still raise substantial revenues. The long-run revenues of the state are apt to be highest from a policy that promotes the rapid and efficient development of wireless communications. Auction revenues are only one piece of the overall revenues. For a country like India, the much more important piece is the promise of long-term sustainable growth. The rapid and efficient development of wireless communications will play a big role in achieving this growth.

\section{Acknowledgments}

Michael Rothkopf has been a frequent source of inspiration to the authors' auction work. This paper is no exception; it builds on Rothkopf and Harstad (1994). The authors thank their colleagues, Lawrence M. Ausubel, Emel Filiz-Ozbay, Erkut Ozbay, and Daniel R. Vincent, for helpful discussions. They thank the National Science Foundation for funding.

\section{Appendix}

Proof of Proposition 1. A bidder's maximization problem is to choose an optimal exit bid. Consider bidder $i$ with a valuation $x_{i} \in\left[P_{t}, P_{t+1}\right)$. Suppose that $\tilde{x}$ is the $(K)$-highest competing bid among bidders other than bidder $i$. First, it is a weakly dominated strategy to submit an exit bid $x^{\prime}<x_{i}$. Suppose, if $\tilde{x} \leq x^{\prime}<x_{i}$, her payoff is equal to the one when she bid her valuation. If $x^{\prime}<\tilde{x} \leq x_{i}$, she loses and is better off bidding her valuation. If $x^{\prime}<x_{i}<\tilde{x}$, she loses regardless. Hence, she cannot be better off bidding $x^{\prime}<x_{i}$. Second, it is also a weakly dominated strategy to submit an exit bid $x^{\prime}>x_{i}$. If $\tilde{x} \leq x_{i}<x^{\prime}$, she receives the same payoff as submitting an exit bid of $x_{i}$. If $x_{i}<\tilde{x} \leq x^{\prime}$, she wins the item at price above her valuation and receives a negative payoff. Finally, if $x_{i}<x^{\prime}<\tilde{x}$, she loses regardless. Thus, she cannot gain by bidding $x^{\prime}>x_{i}$. Therefore, it is a weakly dominant strategy to submit an exit bid equal to the bidder's valuation.

Proof of Lemma 1. In round $t>s+1$, the final price is at least $P_{t-1}$, which exceeds bidder $i$ 's valuation. Winning the item yields a strictly negative payoff regardless of her rank, so that she is better off losing. Thus, it is a weakly dominant strategy to exit immediately in round $t$ to reduce a chance of winning the item if she is a provisional winner or to avoid winning at all if she is a provisional loser.

Proof of Lemma 2. Consider a provisional loser who has a valuation less than the current clock price. Exiting immediately yields a payoff of zero, whereas bidding yields a positive expected payoff because she may win the item in the subsequent round at a profitable price. Thus, a provisional loser will never exit before her valuation is reached.

Next, consider a provisional loser $i$ who has a valuation $x_{i} \in\left[P_{t-1}, P_{t}\right)$ in round $t$. By remaining active, she may be able to win the item at $P_{t-1}$ if fewer than $K-2$ bids in addition to her bid are submitted. However, bidding entails a risk of winning at a price of $P_{t}$, resulting in a negative payoff. According to Lemma 1, if she bids in round $t$ and the auction continues to round $t+1$, she will exit regardless 
of her rank. She will bid if the expected payoff of biddingthe expected payoff if she wins at $P_{t-1}$ less the expected payoff if she wins at $P_{t}$-is positive.

She will win the item at $P_{t}$ when (1) there are at least $K-1$ bids submitted in round $t$, (2) she is selected to be a provisional winner of rank $L$, and (3) less than $L$ bids from provisional losers are submitted in round $t+1$. Let $\lambda_{i t}\left(m, r, \mathbf{H}_{i t}\right)$ be the probability that $m$ bidders out of $r$ remaining bidders excluding bidder $i$ stay active in round $t$ given a ranking history $\mathbf{H}_{i t}$ and $\mu_{i t}\left(m, r, \mathbf{H}_{i t}\right)$ be the probability that $m$ provisional losers out of $r$ provisional losers bid in round $t$ given a ranking history $\mathbf{H}_{i t}$.

Suppose there are $R$ bidders remaining in round $t$. The provisional loser $i$ 's expected payoff is

$$
\begin{aligned}
& \left(x_{i}-P_{t-1}\right) \sum_{j=0}^{K-2} \lambda_{i t}\left(j, R, \mathbf{H}_{t}\right)+\left(x_{i}-P_{t}\right) \lambda_{i t}\left(K-1, R, \mathbf{H}_{t}\right) \\
& \quad+\left(x_{i}-P_{t}\right) \sum_{j=K}^{R} \lambda_{i t}\left(j, R, \mathbf{H}_{t}\right) \sum_{L=1}^{K} \sum_{z=0}^{L-1} \frac{1}{j+1} \mu_{i, t+1}\left(z, j-K+1, \mathbf{H}_{t} \cup(L)\right) .
\end{aligned}
$$

The first term is the expected payoff when less than $K-2$ bids are submitted. The second term is the expected payoff when exactly $K-1$ bids are submitted and the provisional loser $i$ wins the item at $P_{t}$. The third term is the expected payoff when the auction continues to round $t+1$ and the provisional loser $i$ wins the item. The last two summations aggregate probabilities that bidder $i$ is selected as a provisional winner of rank $L=1, \ldots, K$, and $z=0, \ldots, L-1$ bids are submitted in round $t+1$. The first summation in the third term then aggregates over a chance that at least $K$ bids are submitted in round $t+1$.

Because $P_{t-1} \leq x_{i}<P_{t}$ and $\lambda_{i t}\left(m, r, \mathbf{H}_{i t}\right) \geq 0$, the first term is weakly positive, whereas the second and third terms are negative. For some ranking history, an expected payoff when less than $K-2$ bids are submitted is strictly positive. Because bidder $i$ 's valuation is closer to $P_{t}$, the first term is larger, whereas the other two terms become smaller and the expected payoff of bidding increases. By using an intermediate valuation $x_{i}=P_{t}$, the expected payoff of bidding is positive. So, if bidder $i$ 's valuation is sufficiently close to $P_{t}$, the expected payoff is positive, and as a result, bidding is profitable for bidder $i$.

Proof of Lemma 3. Consider a provisional winner $i$ in round $t$ with valuation $x_{i} \in\left[P_{t}, P_{t+1}\right)$. It is optimal to exit in round $t$ if the expected payoff of exiting exceeds the expected payoff of bidding. Using the same notations as in the proof of Lemma 2, suppose there are $R$ bidders remaining in round $t$, and the ranking history is $\mathbf{H}_{i t}$. Let $l$ be a provisional winner $i^{\prime}$ s rank in round $t$. If her valuation is close to $P_{t}$, she will exit in round $t+1$ because a negative expected payoff arising from winning the item at an unprofitable price exceeds an expected payoff of exiting.
It is optimal to exit in round $t$ if

$$
\begin{aligned}
\left(x_{i}-P_{t-1}\right) & \sum_{j=0}^{l-1} \mu_{i t}\left(j, R, \mathbf{H}_{t}\right) \\
> & \left(x_{i}-P_{t}\right) \lambda_{i t}\left(K-1, R, \mathbf{H}_{t}\right)+\left(x_{i}-P_{t-1}\right) \sum_{j=0}^{K-2} \lambda_{i t}\left(j, R, \mathbf{H}_{t}\right) \\
& +\left(x_{i}-P_{t}\right) \sum_{j=K}^{R} \lambda_{i t}\left(j, R, \mathbf{H}_{t}\right) \sum_{L=1}^{K} \sum_{z=0}^{L-1} \frac{1}{j+1} \mu_{i, t+1} \\
& \cdot\left(z, j-K+1, \mathbf{H}_{t} \cup(L)\right) .
\end{aligned}
$$

The left-hand side is the expected payoff if provisional winner $i$ exits and less than $l$ bids are submitted. The first term of the right-hand side is the expected payoff if provisional winner $i$ bids and exactly $l-1$ bids are submitted so that provisional winner $i$ gets the item at $P_{t}$. The second term of the right-hand side is the expected payoff if fewer than $K-1$ bids are submitted so that bidder $i$ gets the item at $P_{t-1}$. The last term is the expected payoff if at least $K-1$ bids are submitted and the auction continues to round $t+1$. Provisional winner $i$ is selected to be a provisional winner of rank $L$ in round $t+1$. She then exits and wins the item at $P_{t}$. Assume for now that bidder $i$ exits in round $t+1$. Later, we will use an intermediate valuation $P_{t}$ so that it is a dominant strategy for provisional winner $i$ to exit in round $t+1$.

Rearranging yields

$$
\begin{aligned}
\left(x_{i}-P_{t-1}\right) \lambda_{i t}\left(K-1, R, \mathbf{H}_{t}\right) & \\
> & \left(x_{i}-P_{t}\right) \lambda_{i t}\left(K-1, R, \mathbf{H}_{t}\right)+\left(x_{i}-P_{t}\right) \sum_{j=K}^{R} \lambda_{i t}\left(j, R, \mathbf{H}_{t}\right) \\
& \cdot \sum_{L=1}^{K} \sum_{z=1}^{L} \frac{1}{j} \mu_{i, t+1}\left(z, j-K+1, \mathbf{H}_{t} \cup(L)\right) .
\end{aligned}
$$

Because $x_{i} \in\left[P_{t}, P_{t+1}\right)$ and $\lambda_{i t}\left(m, r, \mathbf{H}_{i t}\right) \geq 0$ for any $m, r$, and $\mathbf{H}_{i t}$, both sides of the inequality are positive. For some ranking history, the probability that $K-1$ bids are submitted in round $t$ is strictly positive so that the left-hand side is strictly positive as well. As provisional winner $i$ 's valuation is closer to $P_{t}$, the left-hand side is larger while the right-hand side becomes smaller. By using an intermediate valuation, $x_{i}=P_{t}$, the inequality holds. That is, the expected payoff of exiting exceeds that of bidding.

Proof of Proposition 2. According to Lemmas 2 and 3, provisional losers may bid above their valuations, and provisional winners may exit before their valuations are reached. For some ranking history and valuation, a bidder may bid if she is a provisional loser, but she may exit if she is a provisional winner. Such an asymmetric bidding strategy leads to an inefficient allocation.

Proof of Lemma 4. In the one-item case, the final price is equal to the highest bid. Regardless of her rank, a bidder with a valuation $x_{i}<P_{t}$ cannot profitably bid in round $t$ 
because the final price will be at least $P_{t}$. Therefore, bidding above one's valuation is a weakly dominated strategy.

If a bidder with valuation $x_{i} \geq P_{t}$ is a provisional loser in round $t$, it is a weakly dominated strategy to exit because exiting yields a payoff of zero, whereas bidding may give her a chance to win at a profitable price. Hence, the optimal strategy for a provisional loser is straightforward bidding.

Proof of Lemma 5. To show this, consider a provisional winner with valuation $x_{i}$ in round $t$. Let $\lambda_{t}\left(\mathbf{H}_{i t}\right)$ be a probability that the opponent bids in round $s$ given a ranking history $\mathbf{H}_{i t}$ and $\Pi_{t+1}\left(x_{i}, \mathbf{H}_{i t}\right)$ be an expected payoff in round $t+1$ given a valuation $x_{i}$ and a ranking history $\mathbf{H}_{i t}$. Note that $\Pi_{t+1}\left(x_{i}, \mathbf{H}_{i t}\right)$ is increasing in $x_{i}$. A provisional winner's expected gain from exiting in round $t$ is given by

$$
\begin{aligned}
G_{i t}\left(x_{i}, \mathbf{H}_{i t}\right) \equiv & \left(x_{i}-P_{t-1}\right) \lambda_{t}\left(\mathbf{H}_{i t}\right)-\left(x_{i}-P_{t}\right) \lambda_{t}\left(\mathbf{H}_{i t}\right) \\
& -\Pi_{i, t+1}\left(x_{i}, \mathbf{H}_{i t}\right) \\
= & \left(P_{t}-P_{t-1}\right) \lambda_{t}\left(\mathbf{H}_{i t}\right)-\Pi_{i, t+1}\left(x_{i}, \mathbf{H}_{i t}\right) .
\end{aligned}
$$

Because the first term does not depend on $x_{i}$ and the second term is decreasing in $x_{i}$, the gain from exiting is decreasing in $x_{i}$ as well.

Proof of Proposition 3. Weakly dominant strategies are defined in Lemmas 4 and 5.

Proof of Lemma 6. We will show that, in any round $t \leq$ $s-2$, a provisional winner will bid even in the scenario that is the most susceptible to bid shading. Suppose bidder $i$ with a valuation $x_{i} \in\left[P_{t}, P_{t+1}\right)$ is a provisional winner in round $t-2$. Consider a scenario that is most susceptible to bid shading-(1) bidder $i$ has the lowest valuation, $x_{i}=P_{t}$, (2) it is profitable to exit in round $t-1$ given a ranking history, and (3) the lower bound of her opponent's valuation is the lowest, that is, the ranking history implies that $\hat{x}_{t-2}\left(\mathbf{H}_{i, t-2}\right)=P_{t-3}$. Let $\Pi_{i t}\left(x_{i}, \mathbf{H}_{i, t-1}\right)$ be bidder i's expected payoff in round $t$. Her gain from exiting in round $t-2$ is

$$
\begin{aligned}
G_{i, t-2}\left(x_{i}, \mathbf{H}_{i, t-2}\right)= & \left(x_{i}-p_{t-3}\right) \frac{F\left(P_{t-2}\right)-F\left(P_{t-3}\right)}{1-F\left(P_{t-3}\right)} \\
& -\left(x_{i}-p_{t-2}\right) \frac{F\left(P_{t-2}\right)-F\left(P_{t-3}\right)}{1-F\left(P_{t-3}\right)} \\
& -\frac{1}{2}\left(x_{i}-p_{t-2}\right) \frac{F\left(P_{t-1}\right)-F\left(P_{t-2}\right)}{1-F\left(P_{t-3}\right)} \\
& -\frac{1}{2} \Pi_{i t}\left(x_{i}, \mathbf{H}_{i, t-2} \cup(0)\right) \\
= & 3 \frac{\Delta^{2}}{1-F\left(P_{t-3}\right)}-3 \frac{\Delta^{2}}{1-F\left(P_{t-3}\right)} \\
& -\frac{1}{2} \Pi_{i t}\left(x_{i}, \mathbf{H}_{i, t-2} \cup(0)\right) \\
= & -\frac{1}{2} \Pi_{i t}\left(x_{i}, \mathbf{H}_{i, t-2} \cup(0)\right)<0 .
\end{aligned}
$$

The first term is the payoff of exiting when the opponent also exits in round $t-2$. The expected payoff of bidding consists of the last three terms. The second term is a payoff of bidding when the opponent exits in round $t-2$. The third term is a payoff when the opponent bids in round $t-2$, bidder $i$ is selected as a provisional winner in round $t-1$, and the opponent exits in round $t-1$. Because $\Pi_{i t}$ is strictly positive, the gain from exiting in round $t-2$ is negative.

Because a provisional winner $i$ with a valuation $x_{i}=P_{t}$ bids in round $t-2$, according to Lemma 5 , any provisional winner with a valuation $x_{i}>P_{t}$ stays active. In other words, a provisional winner in round $t-2$ with a valuation $x \in$ $\left[P_{t+j}, P_{t+j+1}\right)$ for $j=0,1, \ldots, T-t-2$ or, equivalently, a provisional winner in round $s=t-2-j$ with a valuation $x \in$ $\left[P_{t}, P_{t+1}\right)$ for $j=0,1, \ldots, t-3$ will bid as well.

Proof of Proposition 4. Because the amount of bid shading is limited to only two bid levels according to Lemma 6, the absolute amount of bid shading shrinks as the bid increments become smaller. Moreover, the finer bid increments allow bidders to better express the value differences. Hence, the efficiency in the LAB auction is higher by reducing bid increments.

Proof of Lemma 7. We have to calculate a probability that the final price is $P_{t}$ for $t=0,1, \ldots T-1$. For $t>0$, there are two possible cases: (1) both bidders have valuations in $\left[P_{t}, P_{t+1}\right)$, and (2) one bidder has a valuation in $\left[P_{t-1}, P_{t}\right)$ and the other bidder has a valuation in $\left[P_{t}, 1\right]$. The final price is $P_{0}$ only if both bidders have valuations in $\left[P_{0}, P_{1}\right)$. Thus, the expected revenue is

$$
\begin{aligned}
R_{\mathrm{LAB}}^{\mathrm{SB}}(T)= & P_{0}\left(F\left(P_{1}\right)-F\left(P_{0}\right)\right)^{2} \\
& +\sum_{t=1}^{T-1} P_{t}\left[\left(F\left(P_{t+1}\right)-F\left(P_{t}\right)\right)^{2}\right. \\
& \left.\quad+2\left(1-F\left(P_{t}\right)\right)\left(F\left(P_{t}\right)-F\left(P_{t-1}\right)\right)\right] \\
= & \frac{(T-2)(2 T+3)}{6(T-1)^{2}} .
\end{aligned}
$$

Proof of Lemma 8. The maximum shading strategies are given as follows. A provisional winner does not infer the opponent's valuation from the ranking history. That is, in any round $t$, she maximizes her payoff given that the opponent has a valuation in $\left[P_{t-1}, 1\right]$. Therefore, we can find that $\hat{x}_{t-1}\left(\mathbf{H}_{i, t-1}\right)=P_{t}+(2 / 5) \Delta$ for any $t \geq 2$ and for any $\mathbf{H}_{i, t-1} \in \Theta_{t}$. If the final price is $P_{t}$, there are three possible combinations of bids determining the final price: (1) only a provisional winner exits in round $t,(2)$ only a provisional loser exits in round $t$, and (3) both of them exit in round $t+1$. Because a provisional winner never shades more than two bid levels below her valuation, a ranking history of only three rounds before the final round is relevant. Suppose bidder $i$ is a provisional winner at the final round. Hence, there are eight possible cases with a final price of $P_{t}$ for $t=3,4, \ldots, T-4$, as shown in Table A.1.

We have to calculate a probability that the auction ends at $P_{0}, P_{1}, P_{2}, P_{T-3}$, and $P_{T-2}$ separately because their associated probabilities are different, as shown in Table A.2. 
Table A.1 Possible Scenarios in Which the Final Price Is $P_{t}$ for $t=3,4, \ldots, T-4$

\begin{tabular}{lcccc}
\hline & & \multicolumn{2}{c}{ Valuation } & \\
\cline { 3 - 4 } Case & Ranking history & Provisional winner & Provisional loser & Exiting bidder \\
\hline 1 & $\left(R_{i, t-3}, R_{i, t-2}, R_{i, t-1}, R_{i, t}\right)=(1,1,1,1)$ & {$\left[P_{t}+\frac{2}{5} \Delta, P_{t+1}+\frac{2}{5} \Delta\right)$} & {$\left[P_{t}, 1\right]$} & Provisional winner \\
2 & $\left(R_{i, t-3}, R_{i, t-2}, R_{i, t-1}, R_{i, t}\right)=(1,1,1,1)$ & {$\left[P_{t+1}+\frac{2}{5} \Delta, 1\right]$} & {$\left[P_{t-1}, P_{t}\right)$} & Provisional loser \\
3 & $\left(R_{i, t-3}, R_{i, t-2}, R_{i, t-1}, R_{i, t}\right)=(1,0,1,1)$ & {$\left[P_{t-1}+\frac{2}{5} \Delta, P_{t+1}+\frac{2}{5} \Delta\right)$} & {$\left[P_{t}+\frac{2}{5} \Delta, 1\right]$} & Provisional winner \\
4 & $\left(R_{i, t-3}, R_{i, t-2}, R_{i, t-1}, R_{i, t}\right)=(0,1,1,1)$ & {$\left[P_{t}+\frac{2}{5} \Delta, P_{t+1}+\frac{2}{5} \Delta\right)$} & {$\left[P_{t}, 1\right]$} & Provisional winner \\
5 & $\left(R_{i, t-3}, R_{i, t-2}, R_{i, t-1}, R_{i, t}\right)=(0,1,1,1)$ & {$\left[P_{t+1}+\frac{2}{5} \Delta, 1\right]$} & {$\left[P_{t-1}, P_{t+1}+\frac{2}{5} \Delta\right)$} & Provisional loser \\
6 & $\left(R_{i, t-3}, R_{i, t-2}, R_{i, t-1}, R_{i, t}\right)=(0,0,1,1)$ & {$\left[P_{t-1}, P_{t+1}+\frac{2}{5} \Delta\right)$} & {$\left[P_{t}+\frac{2}{5} \Delta, 1\right]$} & Provisional winner \\
7 & $\left(R_{i, t-2}, R_{i, t-1}, R_{i, t}, R_{i, t+1}\right)=(1,1,1,1)$ & {$\left[P_{t+1}+\frac{2}{5} \Delta, P_{t+2}+\frac{2}{5} \Delta\right)$} & {$\left[P_{t}, P_{t+1}\right)$} & Both \\
8 & $\left(R_{i, t-2}, R_{i, t-1}, R_{i, t}, R_{i, t+1}\right)=(0,0,1,1)$ & {$\left[P_{t+1}+\frac{2}{5} \Delta, P_{t+2}+\frac{2}{5} \Delta\right)$} & {$\left[P_{t}+\frac{2}{5} \Delta, P_{t+1}\right)$} & Both \\
\hline
\end{tabular}

Using Tables A.1 and A.2, we can calculate the expected revenue of the LAB auction with maximum shading strategy as

$$
\begin{aligned}
R_{\mathrm{LAB}}^{\mathrm{MS}}(T)=P_{0}\left[\frac{1}{2} \Delta\left(\frac{12}{5} \Delta\right)\right] & +P_{1}\left[\frac{1}{2} \Delta\left(1-\frac{12}{5} \Delta\right)+\frac{1}{2}(1-\Delta)\left(\frac{12}{5} \Delta\right)+\frac{1}{4} \Delta^{2}\right] \\
+ & P_{2}\left[\frac{1}{4}\left(\frac{12}{5} \Delta\right)\left(1-\frac{12}{5} \Delta\right)+\frac{1}{4} \Delta\left(1-\frac{17}{5} \Delta\right)\right. \\
+ & \left.\frac{1}{4} \Delta(1-2 \Delta)+\frac{1}{8} \Delta^{2}+\frac{1}{8} \Delta\left(\frac{3}{5} \Delta\right)\right] \\
+\sum_{t=3}^{T-4} \frac{1}{8} P_{t}[ & \Delta(1-t \Delta)+\Delta\left(1-(t+1) \Delta-\frac{2}{5} \Delta\right) \\
& +2 \Delta\left(1-t \Delta-\frac{2}{5} \Delta\right)+\Delta(1-t \Delta) \\
& +\left(1-(t+1) \Delta-\frac{2}{5} \Delta\right)\left(\frac{3}{5} \Delta\right)+\left(\frac{12}{5} \Delta\right) \\
& \left.\cdot\left(1-t \Delta-\frac{2}{5} \Delta\right)+\Delta^{2}+\Delta\left(\frac{3}{5} \Delta\right)\right] \\
+\frac{1}{8} P_{T-3}[ & \Delta(1-(T-3) \Delta)+\Delta\left(1-(T-2) \Delta-\frac{2}{5} \Delta\right) \\
& +2 \Delta\left(1-(T-3) \Delta-\frac{2}{5} \Delta\right) \\
& +\Delta(1-(T-3) \Delta)+\left(1-(T-2) \Delta-\frac{2}{5} \Delta\right) \\
& \cdot\left(\frac{3}{5} \Delta\right)+\left(\frac{12}{5} \Delta\right)\left(1-(T-3) \Delta-\frac{2}{5} \Delta\right) \\
& \left.+\Delta\left(\frac{3}{5} \Delta\right)+\left(\frac{3}{5} \Delta\right)^{2}\right] \\
+\frac{1}{8} P_{T-2}[ & (1-(T-2) \Delta)\left(\frac{3}{5} \Delta\right)+\left(\frac{8}{5} \Delta\right) \\
& \cdot\left(1-(T-2) \Delta-\frac{2}{5} \Delta\right)+(1-(T-2) \Delta) \\
& \left.\cdot\left(\frac{3}{5} \Delta\right)+(2 \Delta)\left(1-(T-2) \Delta-\frac{2}{5} \Delta\right)\right] .
\end{aligned}
$$

Replacing $\Delta=1 /(T-1)$ and $P_{t}=t /(T-1)$ with some manipulation yields the expected revenue in Lemma 8.

Proof of Proposition 5. According to Lemmas 7 and 8 , the lower bound and upper bound of the expected revenue converge to $1 / 3$. The expected revenue of the $\mathrm{LAB}$ auction converges to $1 / 3$ as well.

Proof of Lemma 9. The calculation is similar to the proof of Lemma 8 with $\hat{x}_{t-1}\left(\mathbf{H}_{i, t-1}\right)=P_{t}+(2(1-\alpha) /(5(1+\alpha))) \Delta$ for any $t \geq 2$ and for any $\mathbf{H}_{i, t-1} \in \boldsymbol{\Theta}_{t}$ instead.
Proof of Proposition 6. Using the lower bound defined in Lemma 9, we solve for $\alpha \in[0,1)$ such that $\tilde{R}_{\mathrm{LAB}}^{\mathrm{MS}}(T, \alpha)$ $\geq 1 / 3$.

Proof of Proposition 7. The equilibrium bidding function is solved in the \$9. The next step is to prove that if the optimal exit bid is higher than the current clock price, it is optimal to bid at the current clock price. Consider a bidder with a valuation $x$ who bids as if he has a valuation $x^{\prime}$. His payoff function is

$$
\begin{aligned}
\pi_{t}\left(x^{\prime}, x, \mathbf{M}_{t}\right)= & x G\left(x^{\prime} \mid z_{t}\right)-B_{t}\left(x^{\prime}, \alpha, \mathbf{M}_{t}\right) G\left(x^{\prime} \mid z_{t}\right) \\
& -\alpha \int_{x^{\prime}}^{B_{t}^{-1}\left(x^{\prime}, \alpha, \mathbf{M}_{t}\right)} x-B_{t}\left(s, \alpha, \mathbf{M}_{t}\right) d G\left(s \mid z_{t}\right) .
\end{aligned}
$$

Differentiating the payoff function with respect to $x^{\prime}$ yields

$$
\begin{aligned}
\frac{\partial}{\partial x^{\prime}} \pi_{t}\left(x^{\prime}, x, z_{t}\right)= & (1+\alpha)\left(x-B_{t}\left(x^{\prime}, \alpha, \mathbf{M}_{t}\right)\right) g\left(x^{\prime} \mid z_{t}\right) \\
& -B_{t}^{\prime}\left(x^{\prime}, \alpha, \mathbf{M}_{t}\right) G\left(x^{\prime} \mid z_{t}\right) \\
= & (1+\alpha)\left(x-x^{\prime}\right) g\left(x^{\prime} \mid z_{t}\right) \\
& +(1+\alpha)\left(x^{\prime}-B_{t}\left(x^{\prime}, \alpha, \mathbf{M}_{t}\right)\right) g\left(x^{\prime} \mid z_{t}\right) \\
& -B_{t}^{\prime}\left(x^{\prime}, \alpha, \mathbf{M}_{t}\right) G\left(x^{\prime} \mid z_{t}\right) \\
= & (1+\alpha)\left(x-x^{\prime}\right) g\left(x^{\prime} \mid z_{t}\right) .
\end{aligned}
$$

Consider a bidder with valuation $x$ such that $B_{t}\left(x, \alpha, \mathbf{M}_{t}\right)$ $>P_{t}$. She is constrained to bid either at the current clock price or submit and an exit bid between $P_{t-1}$ and $P_{t}$. Because $\pi_{t}\left(x^{\prime}, x, \mathbf{M}_{t}\right)$ is increasing for all $\tilde{x}<x$, it is optimal to bid at the current clock price.

Proof of Proposition 8. According to Proposition 7, the bidding strategy is symmetric and monotonic in valuation; thus, the LABx auction is efficient.

Proof of Proposition 9. The allocation rules and expected payoffs of the lowest-valuation bidder of the HRB and LABx auctions are the same. Furthermore, their payoff functions are the same when $\alpha=0$. Thus, revenue equivalence holds. 
Table A.2 Possible Scenarios in Which the Final Prices Are $P_{0}, P_{1}, P_{2}, P_{T-3}$, and $P_{T-2}$

\begin{tabular}{|c|c|c|c|c|}
\hline \multirow[b]{2}{*}{ Final price } & \multirow[b]{2}{*}{ Ranking history } & \multicolumn{2}{|c|}{ Valuation } & \multirow[b]{2}{*}{ Exiting bidder } \\
\hline & & Provisional winner & Provisional loser & \\
\hline$P_{0}$ & $\left(R_{i 1}\right)=(1)$ & {$\left[P_{0}, P_{2}+\frac{2}{5} \Delta\right)$} & {$\left[P_{0}, 1\right]$} & Both \\
\hline$P_{1}$ & $\left(R_{i 1}\right)=(1)$ & {$\left[P_{0}, P_{2}+\frac{2}{5} \Delta\right)$} & {$\left[P_{1}, 1\right]$} & Provisional winner \\
\hline$P_{1}$ & $\left(R_{i 1}\right)=(1)$ & {$\left[P_{2}+\frac{2}{5} \Delta, 1\right]$} & {$\left[P_{0}, P_{1}\right)$} & Provisional loser \\
\hline$P_{1}$ & $\left(R_{i 1}, R_{i 2}\right)=(1,1)$ & {$\left[P_{2}+\frac{2}{5} \Delta, P_{3}+\frac{2}{5} \Delta\right)$} & {$\left[P_{1}, P_{2}\right)$} & Both \\
\hline$P_{2}$ & $\left(R_{i 1}, R_{i 2}\right)=(1,1)$ & {$\left[P_{2}+\frac{2}{5} \Delta, P_{3}+\frac{2}{5} \Delta\right)$} & {$\left[P_{2}, 1\right]$} & Provisional winner \\
\hline$P_{2}$ & $\left(R_{i 1}, R_{i 2}\right)=(1,1)$ & {$\left[P_{3}+\frac{2}{5} \Delta, 1\right]$} & {$\left[P_{1}, P_{2}\right)$} & Provisional loser \\
\hline$P_{2}$ & $\left(R_{i 1}, R_{i 2}\right)=(0,1)$ & {$\left[P_{1}, P_{3}+\frac{2}{5} \Delta\right)$} & {$\left[P_{2}+\frac{2}{5} \Delta, 1\right]$} & Provisional winner \\
\hline$P_{2}$ & $\left(R_{i 1}, R_{i 2}, R_{i 3}\right)=(1,1,1)$ & {$\left[P_{3}+\frac{2}{5} \Delta, P_{4}+\frac{2}{5} \Delta\right)$} & {$\left[P_{2}, P_{3}\right)$} & Both \\
\hline$P_{2}$ & $\left(R_{i 1}, R_{i 2}, R_{i 3}\right)=(0,1,1)$ & {$\left[P_{3}+\frac{2}{5} \Delta, P_{4}+\frac{2}{5} \Delta\right)$} & {$\left[P_{2}+\frac{2}{5} \Delta, P_{3}\right)$} & Both \\
\hline$P_{T-2}$ & $\left(R_{i, T-6}, R_{i, T-5}, R_{i, T-4}, R_{i, T-3}\right)=(1,1,1,1)$ & {$\left[P_{T-3}+\frac{2}{5} \Delta, P_{T-2}+\frac{2}{5} \Delta\right)$} & {$\left[P_{T-3}, 1\right]$} & Provisional winner \\
\hline$P_{T-2}$ & $\left(R_{i, T-6}, R_{i, T-5}, R_{i, T-4}, R_{i, T-3}\right)=(1,1,1,1)$ & {$\left[P_{T-2}+\frac{2}{5} \Delta, 1\right]$} & {$\left[P_{T-4}, P_{T-3}\right)$} & Provisional loser \\
\hline$P_{T-2}$ & $\left(R_{i, T-6}, R_{i, T-5}, R_{i, T-4}, R_{i, T-3}\right)=(1,0,1,1)$ & {$\left[P_{T-4}+\frac{2}{5} \Delta, P_{T-2}+\frac{2}{5} \Delta\right)$} & {$\left[P_{T-3}+\frac{2}{5} \Delta, 1\right]$} & Provisional winner \\
\hline$P_{T-2}$ & $\left(R_{i, T-6}, R_{i, T-5}, R_{i, T-4}, R_{i, T-3}\right)=(0,1,1,1)$ & {$\left[P_{T-3}+\frac{2}{5} \Delta, P_{T-2}+\frac{2}{5} \Delta\right)$} & {$\left[P_{T-3}, 1\right]$} & Provisional winner \\
\hline$P_{T-2}$ & $\left(R_{i, T-6}, R_{i, T-5}, R_{i, T-4}, R_{i, T-3}\right)=(0,1,1,1)$ & {$\left[P_{T-2}+\frac{2}{5} \Delta, 1\right]$} & {$\left[P_{T-4}, P_{T-2}+\frac{2}{5} \Delta\right)$} & Provisional loser \\
\hline$P_{T-2}$ & $\left(R_{i, T-6}, R_{i, T-5}, R_{i, T-4}, R_{i, T-3}\right)=(0,0,1,1)$ & {$\left[P_{T-4}, P_{T-2}+\frac{2}{5} \Delta\right)$} & {$\left[P_{T-3}+\frac{2}{5} \Delta, 1\right]$} & Provisional winner \\
\hline$P_{T-2}$ & $\left(R_{i, T-5}, R_{i, T-4}, R_{i, T-3}, R_{i, T-2}\right)=(1,1,1,1)$ & {$\left[P_{T-2}+\frac{2}{5} \Delta, 1\right]$} & {$\left[P_{T-3}, P_{T-2}\right)$} & Both \\
\hline$P_{T-2}$ & $\left(R_{i, T-5}, R_{i, T-4}, R_{i, T-3}, R_{i, T-2}\right)=(0,0,1,1)$ & {$\left[P_{T-2}+\frac{2}{5} \Delta, 1\right]$} & {$\left[P_{T-3}+\frac{2}{5} \Delta, P_{T-2}\right)$} & Both \\
\hline$P_{T-1}$ & $\left(R_{i, T-5}, R_{i, T-4}, R_{i, T-3}, R_{i, T-2}\right)=(1,1,1,1)$ & {$\left[P_{T-2}+\frac{2}{5} \Delta, 1\right]$} & {$\left[P_{T-2}, 1\right]$} & Provisional winner \\
\hline$P_{T-1}$ & $\left(R_{i, T-5}, R_{i, T-4}, R_{i, T-3}, R_{i, T-2}\right)=(1,0,1,1)$ & {$\left[P_{T-3}+\frac{2}{5} \Delta, 1\right]$} & {$\left[P_{T-2}+\frac{2}{5} \Delta, 1\right]$} & Provisional winner \\
\hline$P_{T-1}$ & $\left(R_{i, T-5}, R_{i, T-4}, R_{i, T-3}, R_{i, T-2}\right)=(0,1,1,1)$ & {$\left[P_{T-2}+\frac{2}{5} \Delta, 1\right]$} & {$\left[P_{T-2}, 1\right]$} & Provisional winner \\
\hline$P_{T-1}$ & $\left(R_{i, T-5}, R_{i, T-4}, R_{i, T-3}, R_{i, T-2}\right)=(0,0,1,1)$ & {$\left[P_{T-3}, 1\right]$} & {$\left[P_{T-2}+\frac{2}{5} \Delta, 1\right]$} & Provisional winner \\
\hline
\end{tabular}

Because bidders shade their bids in the LABx auction, fear of losing therefore impacts the bidding strategy. In contrast, bidders bid truthfully in the HRB auction so that the strategy is not affected by fear of losing. As the exit bid function is increasing in $\alpha$, the expected revenue of the LABx auction is increasing in $\alpha$ as well.

\section{Solving for the Equilibrium with the Uniform}

Distribution, Fixed Increment, and Four Bid Levels

In this section, define $\pi_{i t}\left(x_{i}, q_{i t}, \mathbf{H}_{i t}\right)$ as bidder $i$ 's expected payoff if she submits $q_{i t} \in\{1,0\}$ given bidder $i$ 's ranking history $\mathbf{H}_{i t}$. Note that we can omit the other bidder's ranking history because it is the complement of bidder $i$ 's ranking history. We will solve for the bidding strategy of the bidder with the lowest valuation first.

First, consider a bidder $i$ with valuation $x_{i} \in\left[P_{0}, P_{1}\right)$. If she is a provisional winner in round 1 , according to Lemma 3, she will exit in round 1.

Next, consider a bidder $i$ with valuation $x_{i} \in\left[P_{1}, P_{2}\right)$. If she is a provisional winner in round 2 , she will exit. When she is a provisional winner in round 1, she will exit as well because

$$
\begin{aligned}
\pi_{i 1}\left(x_{i}, 0,(1)\right) & \equiv\left(x_{i}-P_{0}\right) \frac{F\left(P_{1}\right)-F\left(P_{0}\right)}{1-F\left(P_{0}\right)} \\
& =\left(x_{i}-P_{0}\right) \Delta>\pi_{i 1}\left(x_{i}, 1,(1)\right)
\end{aligned}
$$

$$
\begin{aligned}
\equiv & \left(x_{i}-P_{1}\right) \frac{F\left(P_{1}\right)-F\left(P_{0}\right)}{1-F\left(P_{0}\right)} \\
& +\frac{1}{2}\left(x_{i}-P_{1}\right) \frac{F\left(P_{2}\right)-F\left(P_{1}\right)}{1-F\left(P_{0}\right)} \\
= & \frac{3}{2}\left(x_{i}-P_{1}\right) \Delta .
\end{aligned}
$$

Finally, consider a bidder $i$ with valuation $x_{i} \in\left[P_{2}, P_{3}\right]$. If she is a provisional winner in round 3 , she will exit. When she is a provisional winner in round 2 and $\mathbf{H}_{i 2}=(1,1)$, which implies that the opponent has a valuation in $\left[P_{1}, 1\right]$, she will exit because

$$
\begin{aligned}
\pi_{i 2}\left(x_{i}, 0,(1,1)\right) \equiv & \left(x_{i}-P_{1}\right) \frac{F\left(P_{2}\right)-F\left(P_{1}\right)}{1-F\left(P_{1}\right)} \\
= & \left(x_{i}-P_{1}\right) \frac{\Delta}{1-F\left(P_{1}\right)}>\pi_{i 2}\left(x_{i}, 1,(1,1)\right) \\
\equiv & \left(x_{i}-P_{2}\right) \frac{F\left(P_{2}\right)-F\left(P_{1}\right)}{1-F\left(P_{1}\right)} \\
& +\frac{1}{2}\left(x_{i}-P_{1}\right) \frac{F\left(P_{2}\right)-F\left(P_{1}\right)}{1-F\left(P_{1}\right)} \\
= & \frac{3}{2}\left(x_{i}-P_{2}\right) \frac{\Delta}{1-F\left(P_{1}\right)} .
\end{aligned}
$$

If she is a provisional winner in round 2 and $\mathbf{H}_{i 2}=(0,1)$, then the opponent has a valuation greater than $P_{2}$ and thus 
Cramton and Sujarittanonta: Pricing Rule in a Clock Auction

Decision Analysis 7(1), pp. 40-57, () 2010 INFORMS

Table A.3 Possible Outcomes for All Realizations in Round 1 and $\mathbf{H}_{11}=(1)$

\begin{tabular}{lcccc}
\hline & \multicolumn{4}{c}{ Bidder 2's value } \\
\cline { 2 - 5 } Bidder 1's value & {$\left[P_{0}, P_{1}\right)$} & {$\left[P_{1}, P_{2}\right)$} & {$\left[P_{2}, P_{2}+\frac{2}{5} \Delta\right)$} & {$\left[P_{2}+\frac{2}{5} \Delta, P_{3}\right]$} \\
\hline$\left[P_{0}, P_{1}\right)$ & $P_{0}$ & $P_{1}$ & $P_{1}$ & $P_{1}$ \\
{$\left[P_{1}, P_{2}\right)$} & $P_{0}$ & $P_{1}$ & $P_{1}$ & $P_{1}$ \\
{$\left[P_{2}, P_{2}+\frac{2}{5} \Delta\right)$} & $P_{0}$ & $P_{1}$ & $P_{1}$ & $P_{1}$ \\
{$\left[P_{2}+\frac{2}{5} \Delta, P_{3}\right]$} & $P_{1}$ & Cont. & Cont. & Cont. \\
\hline
\end{tabular}

Table A.4 Possible Outcomes for All Realizations in Round 2 and $\mathbf{H}_{12}=(1,1)$

\begin{tabular}{lcccc}
\hline & \multicolumn{4}{c}{ Bidder 2's value } \\
\cline { 2 - 5 } Bidder 1's value & {$\left[P_{0}, P_{1}\right)$} & {$\left[P_{1}, P_{2}\right)$} & {$\left[P_{2}, P_{2}+\frac{2}{5} \Delta\right)$} & {$\left[P_{2}+\frac{2}{5} \Delta, P_{3}\right]$} \\
\hline$\left[P_{0}, P_{1}\right)$ & - & - & - & - \\
{$\left[P_{1}, P_{2}\right)$} & - & - & - & - \\
{$\left[P_{2}, P_{2}+\frac{2}{5} \Delta\right)$} & - & - & - & - \\
{$\left[P_{2}+\frac{2}{5} \Delta, P_{3}\right]$} & - & $P_{1}$ & $P_{2}$ & $P_{2}$ \\
\hline
\end{tabular}

the opponent will bid according to Lemma 4. Therefore, the provisional winner will also bid in round 2 .

If she is a provisional winner in round 1 , we can calculate $\hat{x} \equiv \hat{x}_{1}((1))$ by solving $\pi_{i 1}(\hat{x}, 0,(1))=\pi_{i 1}(\hat{x}, 1,(1))$ as follows:

$$
\begin{aligned}
&\left(\hat{x}-P_{0}\right) \frac{F\left(P_{1}\right)-F\left(P_{0}\right)}{1-F\left(P_{0}\right)}=\left(\hat{x}-P_{1}\right) \frac{F\left(P_{1}\right)-F\left(P_{0}\right)}{1-F\left(P_{0}\right)} \\
&+\frac{1}{2}\left(\hat{x}-P_{1}\right) \frac{F\left(P_{1}\right)-F\left(P_{0}\right)}{1-F\left(P_{0}\right)} \\
&+\frac{1}{2}\left(\left(\hat{x}-P_{2}\right) \frac{F\left(P_{2}\right)-F\left(P_{1}\right)}{1-F\left(P_{0}\right)}\right. \\
&\left.+\frac{1}{2}\left(\hat{x}-P_{2}\right) \frac{F\left(P_{2}\right)-F\left(P_{1}\right)}{1-F\left(P_{0}\right)}\right), \\
&\left(\hat{x}-P_{0}\right) \frac{\Delta}{1-P_{0}}=\left(\hat{x}-P_{1}\right) \frac{\Delta}{1-P_{0}}+\frac{1}{2}\left(\hat{x}-P_{1}\right) \frac{\Delta}{1-P_{0}} \\
&+\frac{1}{2}\left(\left(\hat{x}-P_{2}\right) \frac{\Delta}{1-P_{0}}+\frac{1}{2}\left(\hat{x}-P_{2}\right) \frac{\Delta}{1-P_{0}}\right), \\
& \hat{x}=P_{2}+\frac{2}{5} \Delta .
\end{aligned}
$$

To calculate the expected revenue, we consider all possible realizations of valuations and outcomes as shown in Tables A.3-A.5.

Outcomes when ranking histories are $\mathbf{H}_{11}=(0), \mathbf{H}_{12}=$ $(0,0)$, and $\mathbf{H}_{12}=(0,1)$ are similar to Tables A.3-A.5, respectively, with bidders 1 and 2 swapped. Therefore,

$$
\begin{aligned}
R_{\mathrm{LAB}}(4)=2\left[\frac{1}{2} P_{0} \Delta\left(\frac{12}{5} \Delta\right)+\frac{1}{2} P_{1}(\Delta\right. & \left.\left(\frac{3}{5} \Delta\right)+\frac{1}{2}(2 \Delta)\left(\frac{12}{5} \Delta\right)+\frac{1}{4} \Delta\left(\frac{3}{5} \Delta\right)\right) \\
& \left.+P_{2}\left(\frac{1}{4} \Delta\left(\frac{3}{5} \Delta\right)+\frac{1}{4}(2 \Delta)\left(\frac{3}{5} \Delta\right)\right)\right] .
\end{aligned}
$$

Table A.5 Possible Outcomes for All Realizations in Round 2 and $\mathbf{H}_{12}=(1,0)$

\begin{tabular}{lcccc}
\hline & \multicolumn{4}{c}{ Bidder 2's value } \\
\cline { 2 - 5 } Bidder 1's value & {$\left[P_{0}, P_{1}\right)$} & {$\left[P_{1}, P_{2}\right)$} & {$\left[P_{2}, P_{2}+\frac{2}{5} \Delta\right)$} & {$\left[P_{2}+\frac{2}{5} \Delta, P_{3}\right]$} \\
\hline$\left[P_{0}, P_{1}\right)$ & - & - & - & - \\
{$\left[P_{1}, P_{2}\right)$} & - & - & - & - \\
{$\left[P_{2}, P_{2}+\frac{2}{5} \Delta\right)$} & - & - & - & - \\
{$\left[P_{2}+\frac{2}{5} \Delta, P_{3}\right]$} & - & $P_{2}$ & $P_{2}$ & $P_{2}$ \\
\hline
\end{tabular}

Substituting $\left(P_{0}, P_{1}, P_{2}, P_{3}\right)=(0,1 / 3,2 / 3,1)$ and $\Delta=1 / 3$ yields an expected revenue of 0.2778 .

\section{References}

Ausubel, L. M., P. Cramton. 2004. Auctioning many divisible goods. J. Eur. Econom. Assoc. 2(April-May) 480-493.

Chwe, M. S.-Y. 1989. The discrete bid first price auction. Econom. Lett. 31 303-306.

Cramton, P., E. Filiz-Ozbay, E. Ozbay, P. Sujarittanonta. 2009. Fear of losing in dynamic auctions: An experimental study. Working paper, University of Maryland, College Park.

David, E., A. Rogers, N. R. Jennings, J. Schiff, S. Kraus, M. H. Rothkopf. 2007. Optimal design of English auctions with discrete bid levels. ACM Trans. Internet Tech. 7(2) Article 12.

Delgado, M. R., A. Schotter, E. Ozbay, E. A. Phelps. 2008. Understanding overbidding: Using the neural circuitry of reward to design economic auctions. Science 321 1849-1852.

Engelbrecht-Wiggans, R. 1989. The effect of regret on optimal bidding in auctions. Management Sci. 35(6) 685-692.

Engelbrecht-Wiggans, R., E. Katok. 2007. Regret in auctions: Theory and evidence. Econom. Theory 33(1) 81-101.

Engelbrecht-Wiggans, R., E. Katok. 2008. Regret and feedback information in first-price sealed-bid auctions. Management Sci. 54(4) 808-819.

Engelbrecht-Wiggans, R., E. Katok. 2009. A direct test of risk aversion and regret in first price sealed-bid auctions. Decision Anal. 6(2) $75-86$.

Filiz-Ozbay, E., E. Y. Ozbay. 2007. Auctions with anticipated regret: Theory and experiment. Amer. Econom. Rev. 97(4) 1407-1418.

Koszegi, B., M. Rabin. 2006. A model of reference-dependent preferences. Quart. J. Econom. 121(4) 1133-1166.

Lange, A., A. Ratan. 2010. Multi-dimensional reference-dependent preferences in sealed-bid auctions-How (most) laboratory experiments differ from the field. Games Econom. Behav. 68(2) 634-645.

Mathews, T., A. Sengupta. 2008. Sealed bid second price auctions with discrete bidding. Appl. Econom. Res. Bull. 1(1) 31-52.

Ministry of Communications and Information Technology. 2008. Auction of $3 \mathrm{G}$ and BWA spectrum. Information memorandum, Department of Telecommunications, Ministry of Communications and Information Technology, Government of India.

Rothkopf, M. H., R. M. Harstad. 1994. On the role of discrete bid levels in oral auctions. Eur. J. Oper. Res. 74(3) 572-581. 